\title{
Winter hydrometeorological extreme events modulated by large-scale atmospheric circulation in southern Ontario
}

\author{
Olivier Champagne ${ }^{1}$, Martin Leduc ${ }^{2}$, Paulin Coulibaly ${ }^{1,3}$, and M. Altaf Arain ${ }^{1}$ \\ ${ }^{1}$ School of Geography and Earth Sciences and McMaster Centre for Climate Change, McMaster University, \\ Hamilton, Ontario, Canada \\ ${ }^{2}$ Ouranos and Centre ESCER, Université du Québec á Montréal, Montréal, Québec, Canada \\ ${ }^{3}$ Department of Civil Engineering, McMaster University, Hamilton, Ontario, Canada
}

Correspondence: Olivier Champagne (champago@mcmaster.ca)

\author{
Received: 25 September 2019 - Discussion started: 27 September 2019 \\ Revised: 3 February 2020 - Accepted: 18 February 2020 - Published: 26 March 2020
}

\begin{abstract}
Extreme events are widely studied across the world because of their major implications for many aspects of society and especially floods. These events are generally studied in terms of precipitation or temperature extreme indices that are often not adapted for regions affected by floods caused by snowmelt. The rain on snow index has been widely used, but it neglects rain-only events which are expected to be more frequent in the future. In this study, we identified a new winter compound index and assessed how large-scale atmospheric circulation controls the past and future evolution of these events in the Great Lakes region. The future evolution of this index was projected using temperature and precipitation from the Canadian Regional Climate Model large ensemble (CRCM5-LE). These climate data were used as input in Precipitation Runoff Modelling System (PRMS) hydrological model to simulate the future evolution of high flows in three watersheds in southern Ontario. We also used five recurrent large-scale atmospheric circulation patterns in north-eastern North America and identified how they control the past and future variability of the newly created index and high flows. The results show that daily precipitation higher than $10 \mathrm{~mm}$ and temperature higher than $5^{\circ} \mathrm{C}$ were necessary historical conditions to produce high flows in these three watersheds. In the historical period, the occurrences of these heavy rain and warm events as well as high flows were associated with two main patterns characterized by high $Z_{500}$ anomalies centred on eastern Great Lakes (HP regime) and the Atlantic Ocean (South regime). These hydrometeorological extreme events will still be associated with the same atmospheric patterns in the near future. The future evolution of the index will be modulated by the internal variability of the climate system, as higher $Z_{500}$ on the east coast will amplify the increase in the number of events, especially the warm events. The relationship between the extreme weather index and high flows will be modified in the future as the snowpack reduces and rain becomes the main component of high-flow generation. This study shows the value of the CRCM5-LE dataset in simulating hydrometeorological extreme events in eastern Canada and better understanding the uncertainties associated with internal variability of climate.
\end{abstract}




\section{Introduction}

According to the actual pathway of greenhouse gases emissions, temperature will continue to rise in the future with serious implications for society (Hoegh-Guldberg et al., 2018). The amount of precipitation, especially for extreme events, is also projected to increase globally (Kharin et al., 2013), due to the acceleration of the hydrological cycle (Trenberth, 1999). Because extreme precipitation has a great societal impact across the world, internationally coordinated climate indices, built from precipitation and temperature data, are widely used to assess the evolution of different weather extremes (Zhang et al., 2011). Some of these indices such as monthly or annual maximum of precipitation can be used to improve flood management. However, in catchments that receive snowfall, a large number of floods may occur due to a combination of temperature and precipitation extreme events such as rain on snow (ROS) (Merz and Blöschl, 2003). The impact of ROS on floods generation has been widely studied in different regions of the world, including central Europe (Freudiger et al., 2014), the Alps (Würzer et al., 2016), the Rocky Mountains (Musselman et al., 2018) or New York State (Pradhanang et al., 2013). The projections of these events can be a challenge because they depend on the ability of the climate model to project the precipitation extremes and the aerial extent of snowmelt (McCabe et al., 2007). The climate model improvements allowed recent studies to project the future evolution of ROS (Jeong and Sushama, 2018; Musselman et al., 2018; Surfleet and Tullos, 2013). However, strong uncertainties in the projections of such events remain, especially due to the internal variability of climate (Lafaysse et al., 2014). These uncertainties, even with the perfect climate model, will never be eradicated due to the inherently chaotic characteristic of the atmosphere (Lorenz, 1963; Deser et al., 2014). ROS indexes are clearly controlled by large-scale atmospheric circulation (Cohen et al., 2015) emphasizing the need to include internal climate variability uncertainties in the future evolution of ROS studies.

The Great Lakes region is one of the areas of the world that is highly impacted by ROS events in winter (Buttle et al., 2016; Cohen et al., 2015). In this region, previous studies found correlations between precipitation (rain and snow) and temperature extremes and large-scale circulation indices. The negative phase of the Pacific North American oscillation $\left(\mathrm{PNA}^{-}\right.$) brings more heavy precipitation events in the region south of the Great Lakes (Mallakpour and Villarini, 2016; Thiombiano et al., 2017) and more snowfall in the region north of the Great Lakes (Zhao et al., 2013), due to high moisture transport over the region (Mallakpour and Villarini, 2016). Another study showed a negative phase of PNA and positive phase of North Atlantic Oscillation (NAO) associated with warm days (Ning and Bradley, 2015). Temperature and precipitation uncertainties associated with climate internal variability have also been assessed in North America using a global climate model large ensemble (GCM-LE) (Deser et al., 2014). These studies generally separate precipitation and temperature while studying compound events, such as ROS, has been recommended recently to improve our understanding of extreme impacts (Leonard et al., 2014). However, the definition of ROS index is also subject to high uncertainties (Kudo et al., 2017) and this index may not be relevant in regions affected by significant rain-only events (Jeong and Sushama, 2018). The goal of this study is to understand the impact of atmospheric circulation on winter hydrometeorological extreme events in the Great Lakes region. We will be using the Canadian Regional Climate Model Large Ensemble (CRCM5-LE), a 50-member regional model ensemble at a $12 \mathrm{~km}$ resolution produced over north-eastern North America with the following objectives:

1. define a regional precipitation and temperature compound index that explains the variability of winter high flows in southern Ontario, which is the most populated area in the Great Lakes region;

2. assess the relationship between this index and the recent large-scale atmospheric circulation;

3. investigate the pertinence of the index to explain the future evolution of projected high flows; and

4. demonstrate how internal variability of climate will modulate the future evolution of atmospheric circulation and number of hydrometeorological extreme events in the region.

\section{Data and methods}

\subsection{Climate data}

Observations of precipitation, minimum temperature and maximum temperature for the winter months (DJF) in the 1957-2012 period were taken from Natural Resources Canada (NRCan) observational dataset (NRCANmet) produced by McKenney et al. (2011). These data were generated from an interpolation of Natural Resources Canada and Environment and Climate Change Canada (ECCC) data archives at $10 \mathrm{~km}$ spatial resolution. The simulated evolution of precipitation and temperature is from CRCM5-LE. CRCM5-LE is a 50 -member regional model ensemble at $12 \mathrm{~km}$ resolution produced over north-eastern North America in the scope of the Québec-Bavaria international collaboration on climate change (ClimEx project; Leduc et al., 2019). CRCM5-LE is the downscaled version of the $310 \mathrm{~km}$ resolution global Canadian Earth system model large ensemble (CanESM2LE; Fyfe et al., 2017; Sigmond et al., 2018). The advantage of using a fine-resolution large ensemble is that the processes at a local scale are better represented than a global ensemble, and the local climate from each member of CRCM5-LE can be related to atmospheric circulation from CanESM2LE. Temperature and precipitation from each member of 


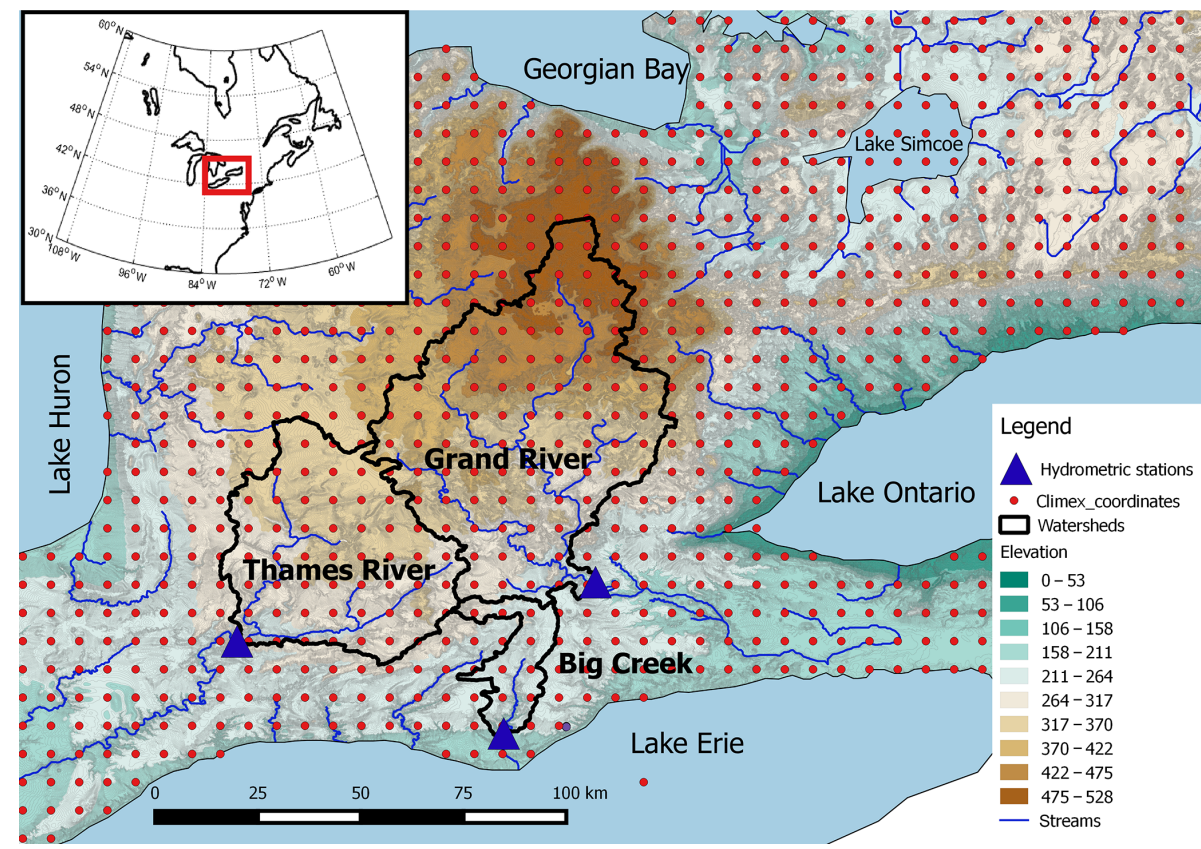

Figure 1. Location of the three watersheds and the ClimEx grid points used in this study and situation in the north-eastern North American domain (inset). Elevation source: High Resolution Digital Elevation Model (HRDEM, Natural Resources Canada).

CRCM5-LE have been bias corrected following the method of Ines and Hansen (2006) and using the observations and CRCM5-LE in the 1957-2012 period. For each month of the year, the intensity distribution of temperature was corrected using a normal distribution. For the bias correction of precipitation, the frequency and the daily intensity were bias corrected separately. The precipitation frequency was first corrected by truncating the modelled frequency distribution in order to match the observed distribution. The truncated distribution of precipitation intensity was then corrected with a gamma distribution (Ines and Hansen, 2006). Each CRCM5-LE grid point has been bias corrected in the 1957-2055 period using the closest NRCANmet point. Using a unique NRCANmet point for each CRCM5-LE point is permitted in our study because of low elevation gradients between points, with the spatial variability of temperature and precipitation being more dependent on the proximity of the lakes than the elevation (Scott and Huff, 1996). The biascorrected CRCM5-LE data are reported at each NRCANmet point.

\subsection{Heavy rain and warm index}

Streamflow observations from three watersheds in southern Ontario (Fig. 1) were used to define the daily temperature and precipitation thresholds needed to generate high flows in winter. A high-flow event was defined for each watershed as streamflow higher than the 99th percentile. When more than $2 \mathrm{~d}$ in a row were selected, the events were considered as a single event and only the day with the highest high flow was considered. Figure 2 shows for each high-flow event the distribution of daily temperature and precipitation amounts from all grids of the watersheds. Only events that produced high flows at least in two of the three watersheds are shown in Fig. 2. The precipitation and temperature data are from the day situated $3 \mathrm{~d}$ before the high-flow event for Big Creek watershed and $2 \mathrm{~d}$ before the high-flow event for the Thames and Grand rivers. This lag corresponds to the delay between a rainfall and/or warm event and the peak flow at the outlet. Figure 2 shows a maximum temperature higher than $5^{\circ} \mathrm{C}$ and precipitation higher than $10 \mathrm{~mm}$ for most grid points during the high-flow events. The index is therefore defined by the number of days with a temperature higher than $5{ }^{\circ} \mathrm{C}$ and precipitation higher than $10 \mathrm{~mm}$. This index defines days with a significant rain and warm event that has the potential to generate a high-flow event. The $5^{\circ} \mathrm{C}$ threshold gives a strong indication that precipitation is in a form of rain, and that the eventual snow in the ground is melting. This index is similar to the ROS index defined by previous studies. The threshold of $10 \mathrm{~mm}$ was previously used to define ROS events with flood potential (Cohen et al., 2015; Musselman et al., 2018). Our newly created index can be defined rather as a heavy rain and warm index because snowpack is not integrated in the calculation.

\subsection{Atmospheric circulation patterns}

The recurrent atmospheric patterns in north-eastern NorthAmerica were identified by a weather regimes technique computed by a $k$-means algorithm (Michelangeli et al., 


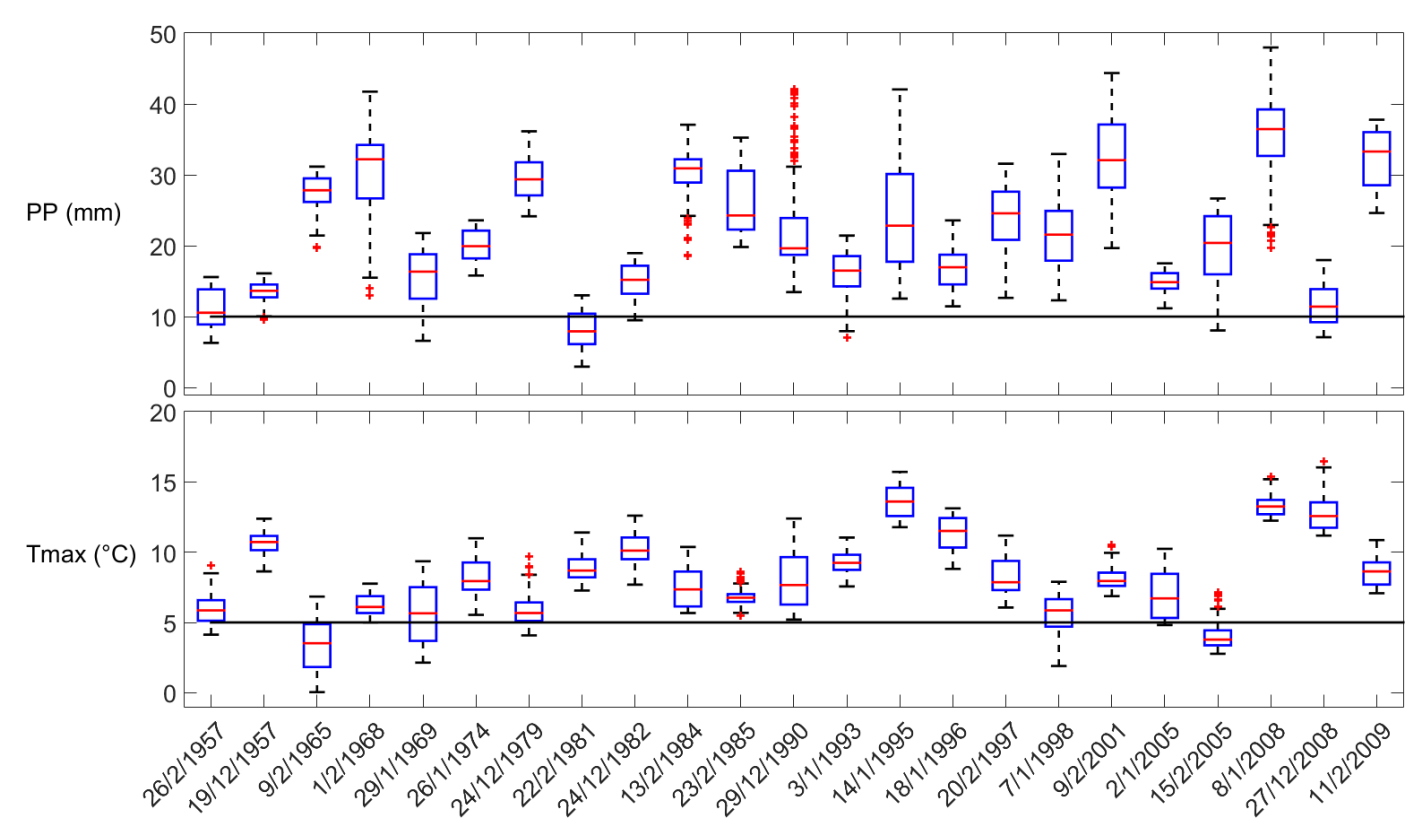

Figure 2. Distribution of NRCANmet temperature and precipitation from all three watersheds grid points corresponding to each DJF highflow event. Boxes extend from the 25 th to the 75 th percentile, with a horizontal red bar showing the median value. The whiskers are lines extending from each end of the box to the 1.5 interquartile range. Plus signs correspond to outliers. The horizontal black lines correspond to the thresholds used to define DJF weather extreme events.

1995). The algorithm used daily geopotential height anomalies at the $500 \mathrm{hPa}$ level $\left(Z_{500}\right)$ from the 20th century reanalyses (20thCR; Compo et al., 2011) and was applied in the 1957-2012 period to the north-eastern part of North America $\left(30-60^{\circ} \mathrm{N}, 110-50^{\circ} \mathrm{W}\right)$. Prior to the $k$-means calculations, we identified the principal components of the $Z_{500}$ maps that explain $80 \%$ of the spatial variance. These principal components have been decomposed in weather regimes thanks to the $k$-means algorithm. The $k$-means algorithm identifies classes of centroids using an iteration method that minimizes intra-regime Euclidean distance and maximizes interregime Euclidean distance between the principal components of each day. The algorithm is repeated 100 times for each number of a class between 2 and 10. The choice of the final class number is decided by a red noise test. This test consists in assessing the significance of the decomposition against weather regimes calculated from 100 randomly generated theoretical datasets that have the same statistical properties than the original dataset. The weather regimes have been previously calculated for the same domain and the red noise test showed five classes as the most robust choice (Champagne et al., 2019a).

The eigenvectors of the principal components calculated with 20thCR have been used to calculate the daily principal components for each member of CanESM2-LE. This transformation was applied to the daily $Z_{500}$ normalized anomalies calculated for periods of 30 years between 1950 and 2099. By calculating the anomalies for periods of 30 years, we minimized the low-frequency variability. There- fore, the internal variability of climate through the 50 members can be fully investigated. Each day of the principal component dataset was then placed to the closest class centroid among the five classes previously identified using the historical 20thCR $Z_{500}$ anomalies. This process was done for each member of CanESM2-LE.

\subsection{Hydrological modelling}

The future evolution of high flows in the three watersheds has been simulated using the Precipitation Runoff Modelling System (PRMS). PRMS is a semi-distributed conceptual hydrological model widely used in snow-dominated regions (Dressler et al., 2006; Liao and Zhuang, 2017; Mastin et al., 2011; Surfleet et al., 2012; Teng et al., 2017, 2018). PRMS computes the water flowing between hydrological reservoirs (plan canopy interception, snowpack, soil zone, subsurface) for each hydrological response unit (HRU). For a general description of PRMS, the reader is referred to Markstrom et al. (2015). Champagne et al. (2019a) previously applied PRMS to these three watersheds and extensively described the parametrization process. PRMS has been calibrated in the 1989-2009 period using precipitation, minimum temperature and maximum temperature from NRCANmet. The three-step trial-and-error calibration approach applied to each watershed showed satisfactory results (Champagne et al., 2019a). The streamflow was simulated for each member of the ensemble in the 1957-2055 period using CRCM5-LE biascorrected data described in Sect. 2.1. 


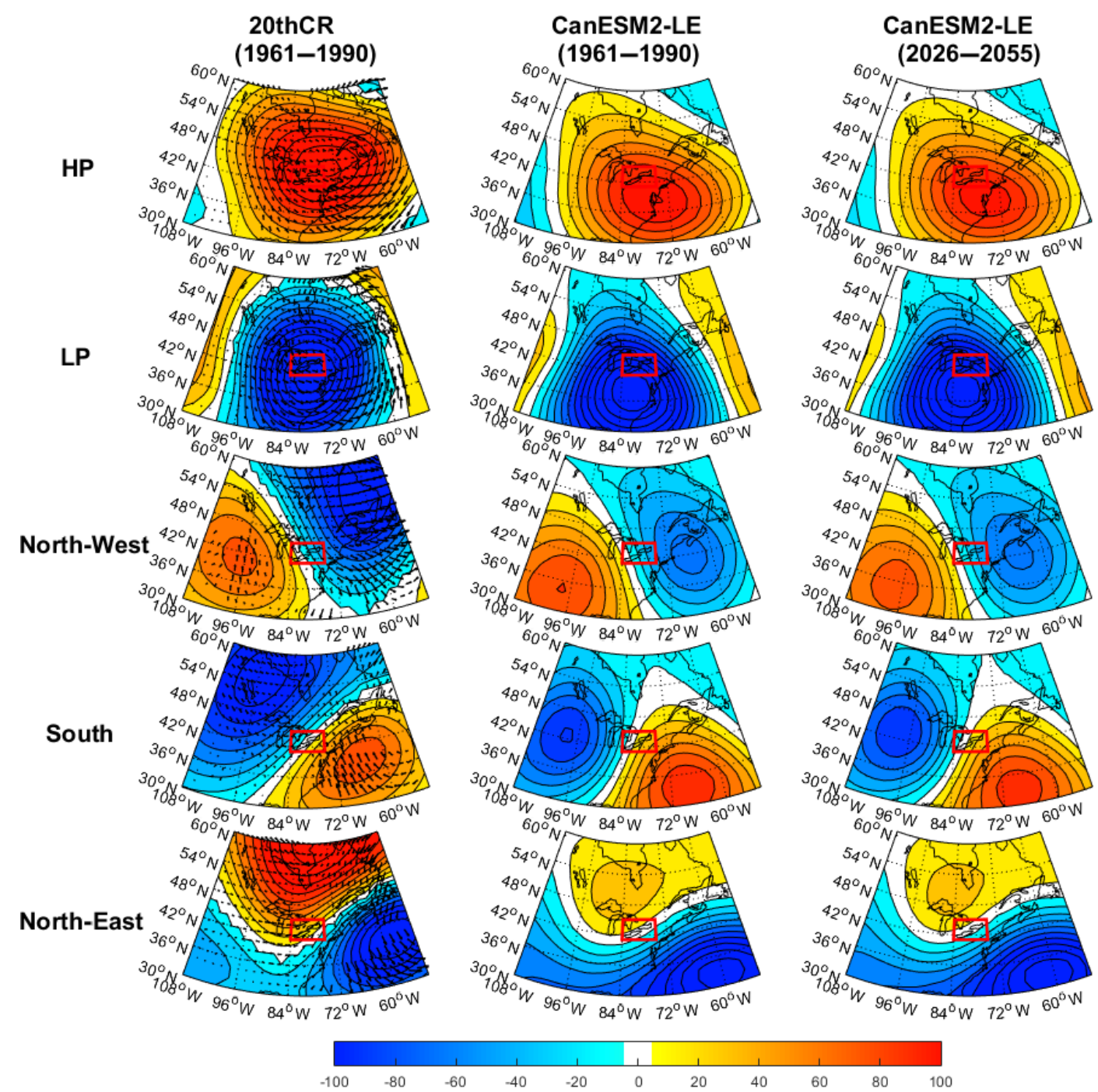

Figure 3. Left panels: DJF $Z_{500}$ anomalies (colours) and winds (vectors) corresponding to weather regimes calculated with 20 thCR in the 1961-1990 period. Middle panels: DJF 50-member average $Z_{500}$ anomalies calculated with CanESM2-LE in the 1961-1990 period. Right panels: DJF 50-member average $Z_{500}$ anomalies calculated with CanESM2-LE in the 2026-2055 period.

To quantify the winter change in number of high flows due to a change in number of weather extreme events, the theoretical high-flow frequency change due to the occurrence change in number of heavy rain and warm events (OCC) has been calculated. For each member of the ensemble, the simulated historical number of high-flow events (99th percentile) associated with each weather regime has been multiplied by the change factor between number of rain and warm events in the historical period (1961-1990) and in the future period (2026-2055). The difference between this calculated number of high flows and the historical number of high flows corresponds to OCC. The total change in number of high flows simulated by PRMS (TOT) corresponding to each weather regime is finally subtracted by OCC for each ensemble member to account for a change in the number of high flows that is not due to a change in number of heavy rain and warm events (DIF).

\section{Results}

\subsection{Weather regimes in north-eastern North America}

A total of five weather regimes have been identified in northeastern North America according to the red noise test and show distinct weather patterns (Fig. 3). The weather regimes computed with 20thCR data show two clear opposite patterns characterized by positive (HP) and negative (LP) geopotential height anomalies on the Great Lakes. The South regime was characterized by positive $Z_{500}$ anomalies in the Atlantic Ocean and negative anomalies in the north-west part of the domain and was associated with southerly winds. The 

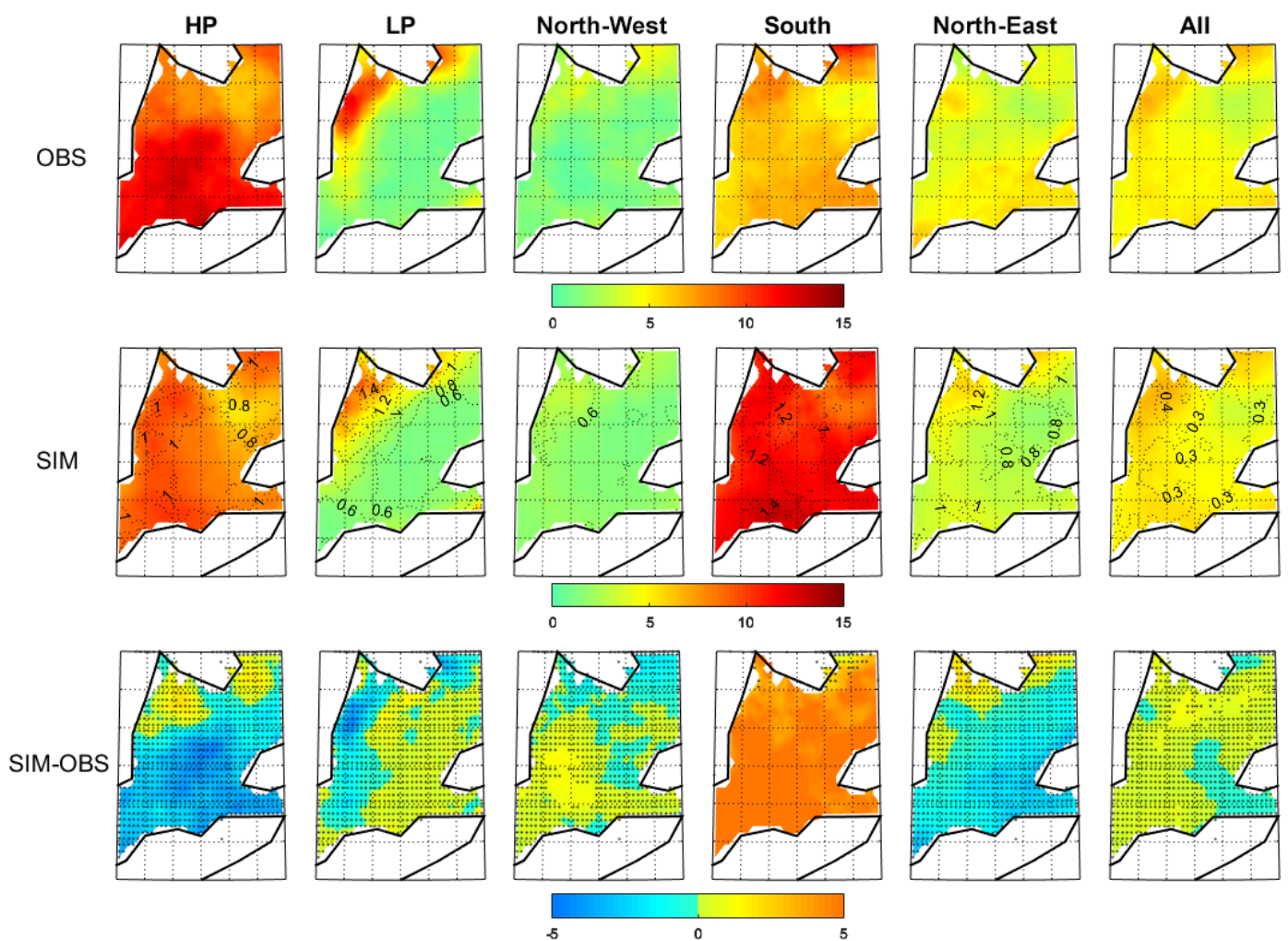

Figure 4. Percentage of DJF number of precipitation events $(P>10 \mathrm{~mm})$ relative to DJF occurrence of weather regimes in the historical period (1961-1990) for the observations (upper panels), simulations from the CRCM5-LE 50-member average (middle panels) and simulations minus observations (lower panels). The dotted lines in the middle panels represent the standard deviation of the 50-member CRCM5-LE simulated percentage. Stippled regions in the lower panels indicate where the observations lie within the CRCM5-LE ensemble spread.

North-West regime had low geopotential height on the Gulf of Saint Lawrence together with winds from the north-west over the Great Lakes region. Finally, the North-East regime was associated with low geopotential height in the Atlantic Ocean but high geopotential height close to the Arctic that drove north-eastern winds over the Great Lakes. The weather regimes calculated with CanESM2-LE data, using the $k$ means centroids identified with 20thCR anomalies, have very similar patterns in the historical period (1961-1990) (Fig. 3). The CanESM2 50-member average $Z_{500}$ anomalies were generally less strong than the 20thCR weather regimes and the anomalies were slightly shifted to the south. Over the Great Lakes, 20thCR and CanESM2-LE $Z_{500}$ anomalies were similar for most of the regimes except for the South regime, which shows higher $Z_{500}$ anomalies with CanESM2LE. In the 2026-2055 period, the weather regimes show meteorological systems in similar locations (Fig. 3).

\subsection{Validation of heavy rain and warm index and high flows simulated by CRCM5-LE}

The ability of the bias-corrected CRCM5-LE data to recreate the number of heavy rain and warm events relative to the number of occurrences of each weather regime is assessed in this section. For the heavy precipitation events, the observations show higher number of events during the occurrence of the HP regime (10\% of all HP days) compared to other regimes, especially in the southern parts of the region (13\% of all HP days) (Fig. 4). The South regime shows the second largest occurrence of heavy precipitation events (7\% of all South days), while the North-West regime was associated with the least number of observed heavy precipitation events ( $2 \%$ of all North-West days). The number of precipitation events associated with an LP regime is spatially variable with a large number of events limited to the Lake Huron shoreline (12\% of all LP days). The number of heavy precipitation events per winter was generally well recreated by the regional ensemble in the historical period (Fig. 4). The South regime is the exception with much more events with the 50-member average (11\% of all South days) compared to the observations ( $7 \%$ of all South days). In southern areas, the simulations also slightly overestimated the number of heavy precipitation events during the North-West regime while underestimating those during the HP regime (Fig. 4).

Figure 5 shows that observed warm events $(7.5 \%$ of all days) were overall more frequent than heavy precipitation events (5\% of all days; Fig. 4). Warm events occurred more frequently in southern areas, particularly on the Niagara 

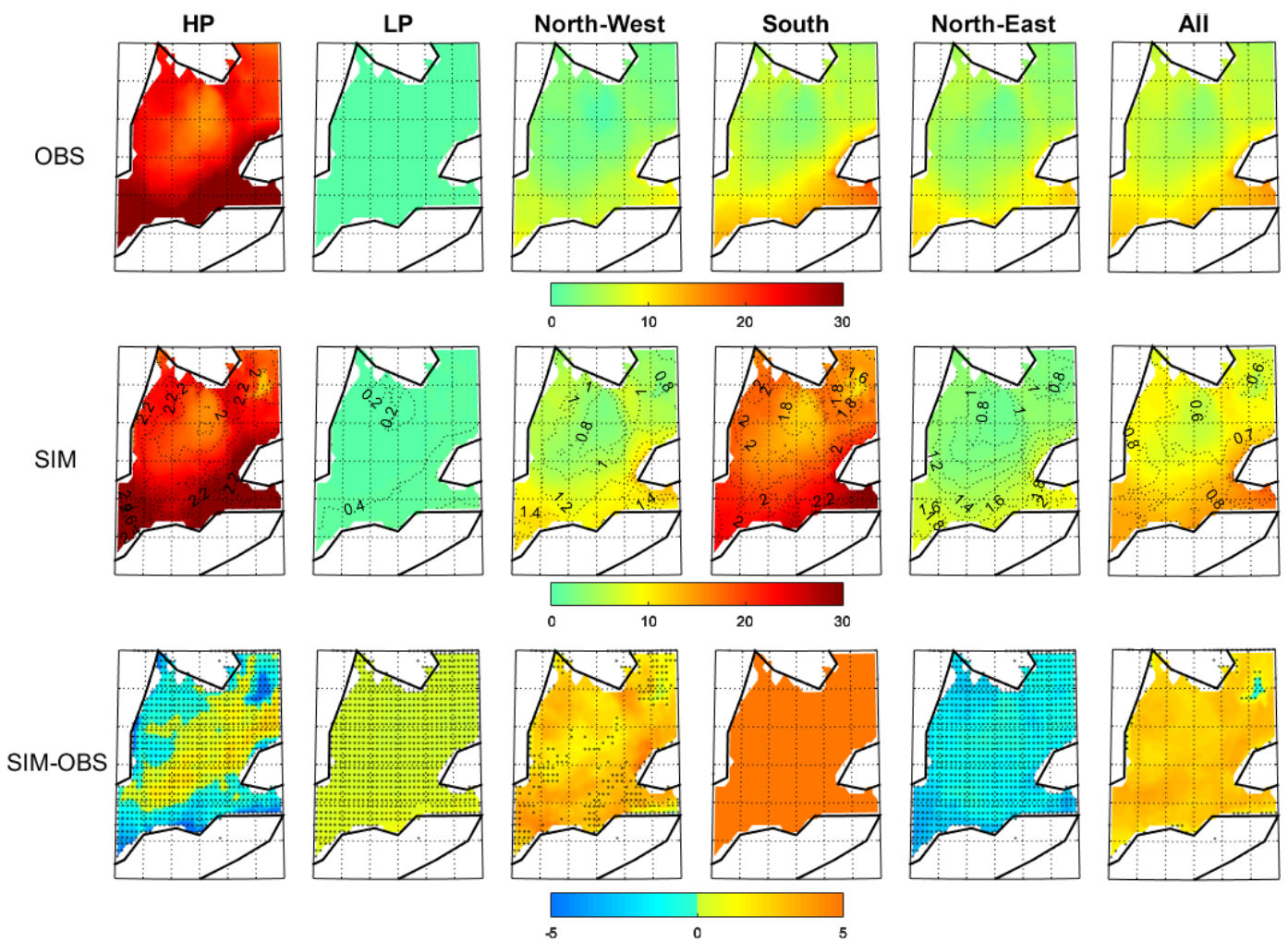

Figure 5. Percentage of DJF number of warm events $\left(T>5^{\circ} \mathrm{C}\right)$ relative to DJF occurrence of weather regime in the historical period $(1961-$ 1990) for the observations (upper panels), simulations from CRCM5-LE 50-member average (middle panels) and simulations minus observations (lower panels). The dotted lines in the middle panels represent the standard deviation of the 50-member CRCM5-LE simulated percentage. Stippled regions in the lower panels indicate where the observations lie within the CRCM5-LE ensemble spread.

Peninsula between Lake Erie and Lake Ontario, where $12 \%-$ $14 \%$ of all days were considered as warm days (Fig. 5). The observed warm events occurred mostly during the HP regime ( $23 \%$ of all HP days), while they were non-existent during the LP regime (Fig. 5). The number of warm events was similar between the North-West, North-East and South regimes in a large part of the area. On the Niagara Peninsula, more events occurred during a South regime $(15 \%$ of all South days). The simulated number of warm events averaged for all members overestimated the observations and represented $11 \%$ of all days (Fig. 5). This discrepancy was due to an overestimation during the North-West and South regimes (Fig. 5). Specifically, the number of events per occurrence of the South regime for the 50-member average (19\% of all South days) was twice the number of events calculated with the observations $(9 \%)$.

Compound heavy rain and warm temperature events were more frequent in the area close to Lake Erie in both observations and simulations if we consider all weather regimes together (Fig. 6). The number of events was overestimated by the ensemble mean in the northern parts of the region. In this region, many grid points show all members of the ensemble overestimating the number of events. Close to Lake Erie, the overestimation was lower and even non-existent on the Niagara Peninsula. These compound index heavy rain and warm events were more frequent during an HP regime in both observations and simulations ( $4.5 \%$ of all HP days). The simulations show a similar number of events during a South regime ( $4.5 \%$ of all South days), but the results largely overestimated the observations ( $1.5 \%$ of all South days). Finally, the occurrences of events were very low for LP and North-West (Fig. 6).

The historical distributions of streamflow associated with heavy rain and warm events for the observed streamflow (OBS), streamflow simulated with NRCANmet (CTL) and streamflow simulated for all CRCM5-LE members (ENS) are depicted in Fig. 7. The results show an observed streamflow frequently higher than the high-flow threshold when the heavy rain and warm events occurred during an HP regime. The streamflow simulated with NRCANmet weather data (CTL) is underestimated but shows a similar inter-regime variability with higher streamflow during HP heavy rain and warm events compared to events associated with other weather regimes. The 50 simulations from CRCM5-LE show a less strong variability between weather regimes but again higher streamflow when heavy rain and warm events correspond to the HP regime. High flows also 

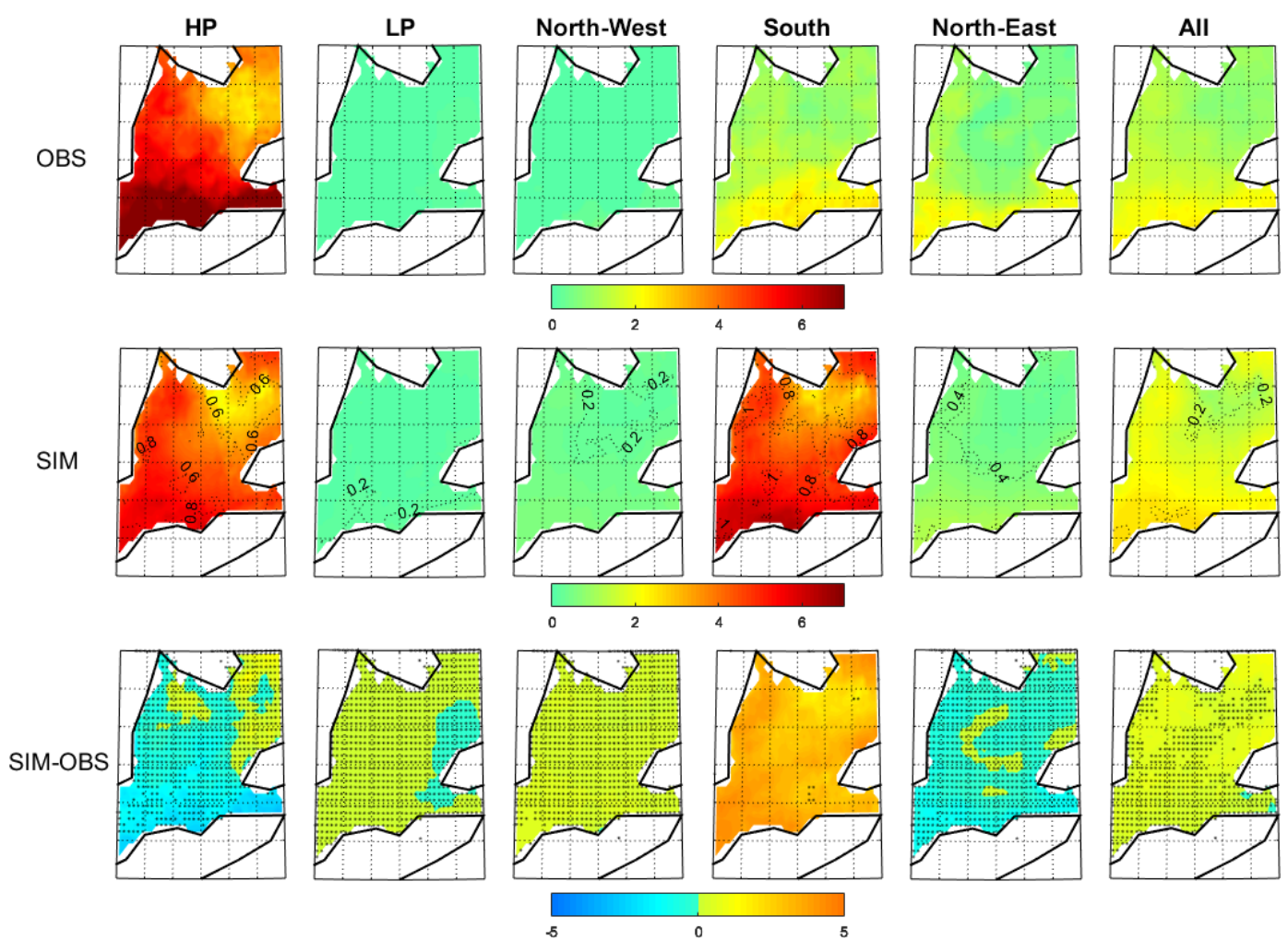

Figure 6. Percentage of DJF number of heavy rain and warm events $\left(P>10 \mathrm{~mm}\right.$ and $\left.T>5^{\circ} \mathrm{C}\right)$ relative to DJF occurrence of weather regimes in the historical period (1961-1990) for the observations (upper panels), simulations from CRCM5-LE 50-member average (middle panels) and observations minus simulations (lower panels). The dotted lines in the middle panels represent the standard deviation of the 50member CRCM5-LE simulated percentage. Stippled regions in the lower panels indicate where the observations lie within the CRCM5-LE ensemble spread.

occur for other weather regimes, especially the South regime (Fig. 7).

\subsection{Future evolution of hydrometeorological extreme events}

The number of heavy precipitation events simulated by CRCM5-LE is expected to increase between 1961-1990 and 2026-2055, with a maximum increase between one and two events per winter expected close to the Georgian Bay (Fig. 8). The increase in the number of events is mainly expected during the South regime but also for the LP regime near Lake Huron. The increased frequency of warm events is expected to be even higher, reaching a total increase of about 10 events per winter close to Lake Erie. The highest increase is expected for HP and South regimes and at a lower rate for regimes North-East and North-West. The number of compound events is expected to increase by one or two events per winter, with a maximal increase between Lake Erie and Lake Huron. The increase in the number of heavy rain and warm events is expected to concern mainly the South regime and HP (Fig. 8).
The contribution of the trend in heavy rain and warm events to the trend in the number of high flows has been investigated (Fig. 9). Taking all weather regime events together, the total change in number of high flows simulated by PRMS (TOT) is expected to increase in the future. The theoretical high-flow frequency change due to the occurrence change in number of heavy rain and warm events (OCC) is slightly lower than the increase in TOT for most of the weather regimes (DIF positive; Fig. 9). The HP regime shows an opposite result, with higher OCC compared to TOT on average (DIF negative, Fig. 9).

The 50-member distribution change in rainfall and snowfall amounts corresponding to all compound events simulated by PRMS at each watershed outlet has been investigated (Fig. 10). The amount of snowmelt and rainfall taken together is generally decreasing, but a large difference between members was simulated. Many members show an increase in the amount of rain and snowmelt, especially during the LP regime. The change in the amount of snowmelt follows a similar decreasing trend for most of the cases but an increase in snowmelt during LP extreme days is expected, especially in the Grand River. The amount of rainfall slightly increases 


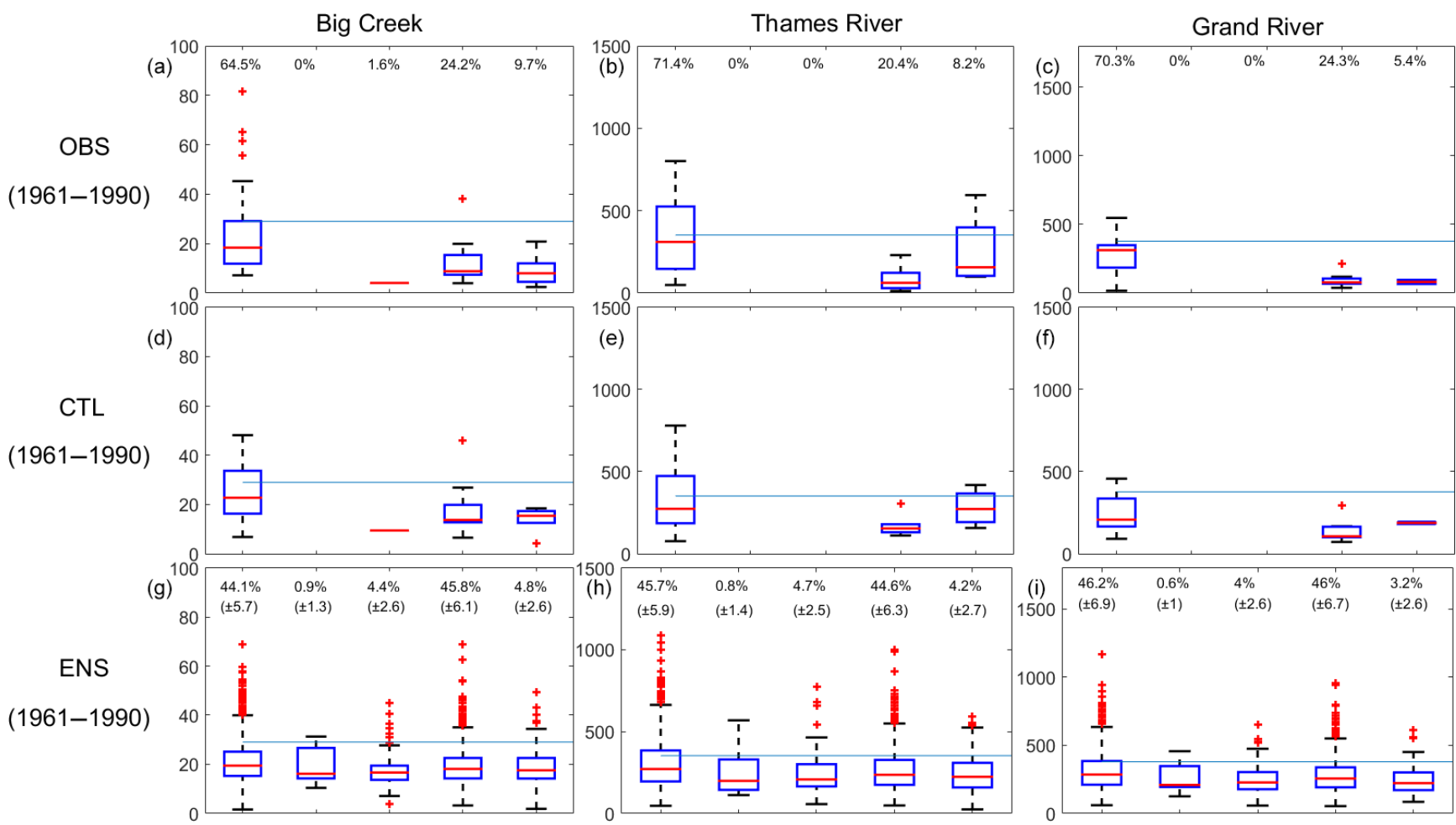

Figure 7. Upper and middle panels: distribution of observed (OBS) and simulated (CTL) streamflow corresponding to all observed heavy rain and warm events. Lower panels: distribution of simulated streamflow corresponding to all simulated heavy rain and warm events pooled for all members (ENS). Boxes extend from the 25th to the 75th percentile, with a horizontal red bar showing the median value. The whiskers are lines extending from each end of the box to the 1.5 interquartile range. Plus signs correspond to outliers. The horizontal blue lines correspond to the high-flow threshold (99th percentile).

for most of the members, especially for LP in Thames River and Big Creek River.

\subsection{Relationship between change in occurrence of weather regimes and extreme events}

Correlations between change in occurrence of weather regimes and change in number of rain and warm events between 1961-1990 and 2026-2055 for the 50 members have been calculated for each grid point (Fig. 11). The magnitude of the correlations between occurrence of weather regimes and warm events is higher compared to correlations with heavy precipitation events. The results show significant positive correlations ( $95 \%$ confidence) between warm events and the change in occurrence of the HP regime and negative correlations (95\% confidence) between warm events and the change in occurrence of LP-North-East regimes. For the precipitation events, the results varied spatially, with few areas showing positive correlations for the South regime (Fig. 11). The compound index shows positive correlations between the number of events and the HP regime close to Lake Erie and negative correlations between the number of events and the LP regime near Lake Huron.
Inter-member correlations between the change in the frequency of a combination of weather regimes and the change in the frequency of heavy rain and warm events, averaged over the entire region, have also been investigated (Table 1). The goal is to identify the impact of a combination of two weather patterns on the hydrometeorological events. The weather regimes are a discretization of a continuous process, and the combination of weather regimes aims to show the impact of weather regime interactions on local climate. The combinations of weather regimes have been made by summing the change of occurrence from the two regimes of each combination. The correlation between change of any weather regimes combinations and change in number of heavy precipitation events is not significant. The correlations between change in number of warm events and change in occurrence of weather regimes are increased when the South regime is calculated with the HP regime and when the LP regime is calculated with the North-East regime compared to correlations with HP or LP regimes only (Table 1). Concerning the compound index, the number of heavy rain and warm events is positively correlated with a combination of the HP-South regime (significant at $95 \%$ confidence interval) and negatively correlated with a combination of North-East-LP and North-West-LP (significant at $90 \%$ confidence interval). 

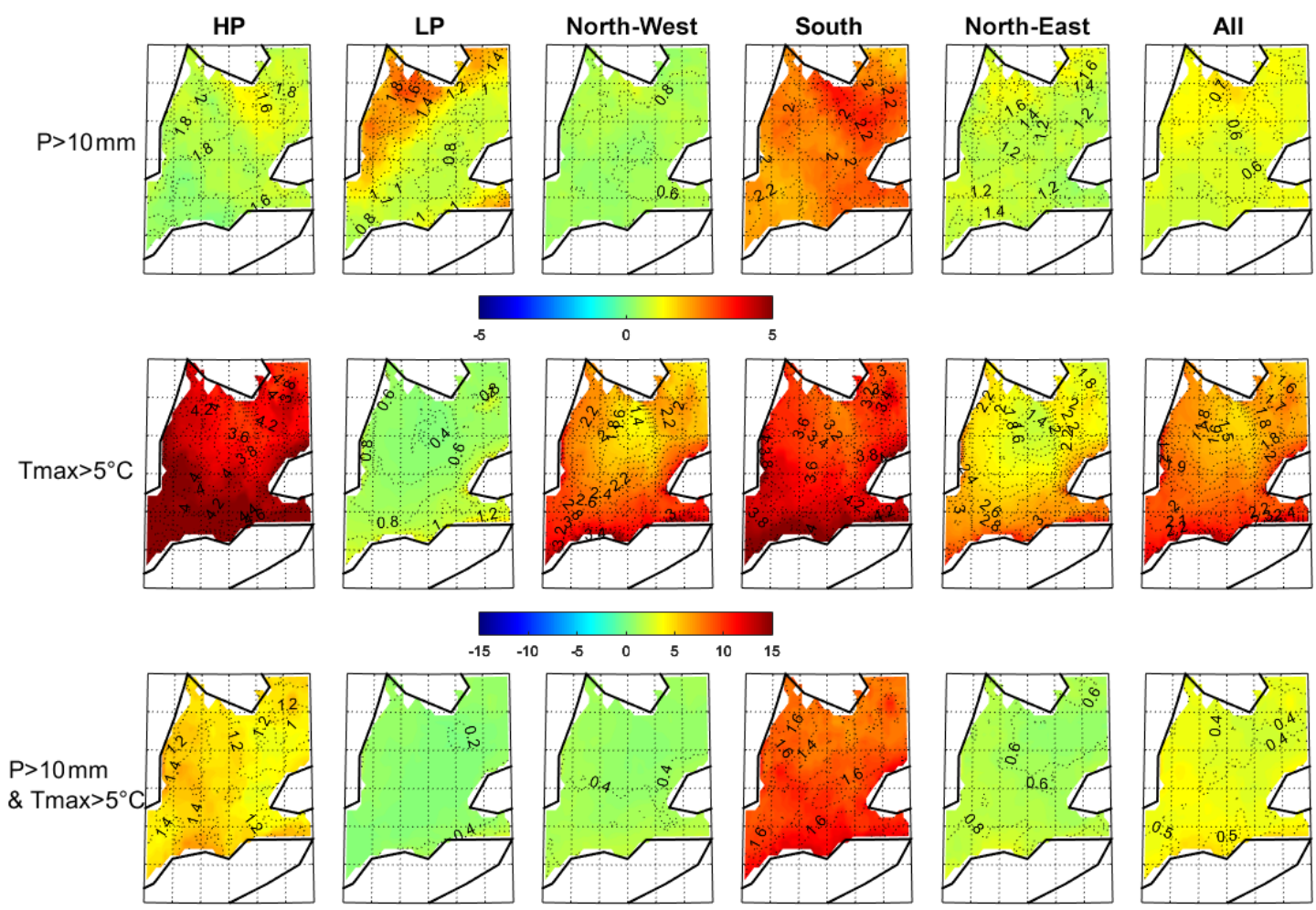

Figure 8. DJF change in CRCM5-LE average percentage of days with precipitation and warm events relative to DJF occurrence of weather regimes between the historical (1961-1990) and the future period (2026-2055). The dotted lines represent the standard deviation of the 50-member CRCM5-LE simulated change.

Table 1. Inter-member correlations between DJF change in occurrence of weather regimes and DJF change in number of events between 1961-1990 and 2026-2055. Bold text shows correlation significance at the 90\% confidence level, underlined text shows correlation significance at $95 \%$, and italic text shows correlation significance at $99 \%$ according to the Pearson correlation table.

\begin{tabular}{|c|c|c|c|c|c|c|c|c|c|c|c|c|c|c|c|}
\hline & \multicolumn{5}{|c|}{$P>10 \mathrm{~mm}$} & \multicolumn{5}{|c|}{$T_{\max }>5^{\circ} \mathrm{C}$} & \multicolumn{5}{|c|}{$P>10 \mathrm{~mm}$ and $T_{\max }>5^{\circ} \mathrm{C}$} \\
\hline & HP & LP & NW & $\mathrm{S}$ & $\mathrm{NE}$ & $\mathrm{HP}$ & LP & NW & $S$ & $\mathrm{NE}$ & HP & LP & NW & $S$ & $\mathrm{NE}$ \\
\hline HP & 0.02 & -0.04 & -0.05 & 0.10 & 0.06 & 0.45 & 0.20 & 0.38 & 0.48 & 0.20 & $\underline{0.30}$ & 0.10 & 0.21 & $\underline{0.35}$ & 0.18 \\
\hline LP & & -0.08 & -0.14 & 0.02 & -0.01 & & -0.38 & -0.23 & -0.25 & -0.45 & & $\underline{-0.29}$ & -0.23 & $-\overline{0.17}$ & -0.27 \\
\hline NW & & & -0.08 & -0.01 & -0.04 & & & 0.02 & 0.01 & -0.20 & & & -0.04 & -0.02 & -0.13 \\
\hline S & & & & 0.10 & 0.12 & & & & -0.01 & -0.21 & & & & 0.03 & -0.06 \\
\hline NE & & & & & 0.06 & & & & & -0.25 & & & & & -0.10 \\
\hline
\end{tabular}

Table 2. Inter-member correlations between DJF change in occurrence of weather regimes and DJF change in number of high-flow events between 1961-1990 and 2026-2055. Bold text shows correlations significant at 90\% according to the Pearson correlation table. Underlined text shows correlation significance at $95 \%$.

\begin{tabular}{|c|c|c|c|c|c|c|c|c|c|c|c|c|c|c|c|}
\hline & \multicolumn{5}{|c|}{ Big Creek } & \multicolumn{5}{|c|}{ Thames River } & \multicolumn{5}{|c|}{ Grand River } \\
\hline & HP & LP & NW & $S$ & NE & $\mathrm{HP}$ & LP & NW & $\mathrm{S}$ & NE & HP & LP & NW & $\mathrm{S}$ & $\mathrm{NE}$ \\
\hline HP & 0.00 & -0.18 & 0.18 & 0.04 & -0.08 & 0.06 & -0.02 & 0.11 & 0.04 & 0.04 & -0.05 & -0.27 & 0.13 & 0.10 & -0.10 \\
\hline LP & & -0.24 & 0.05 & -0.12 & -0.25 & & -0.12 & -0.02 & -0.11 & -0.10 & & -0.31 & -0.01 & -0.07 & $\underline{-0.28}$ \\
\hline NW & & & 0.22 & 0.23 & 0.14 & & & 0.07 & 0.03 & 0.06 & & & 0.20 & $\underline{0.29}$ & 0.14 \\
\hline S & & & & 0.05 & -0.05 & & & & -0.04 & -0.05 & & & & 0.18 & 0.06 \\
\hline $\mathrm{NE}$ & & & & & -0.11 & & & & & -0.02 & & & & & -0.09 \\
\hline
\end{tabular}



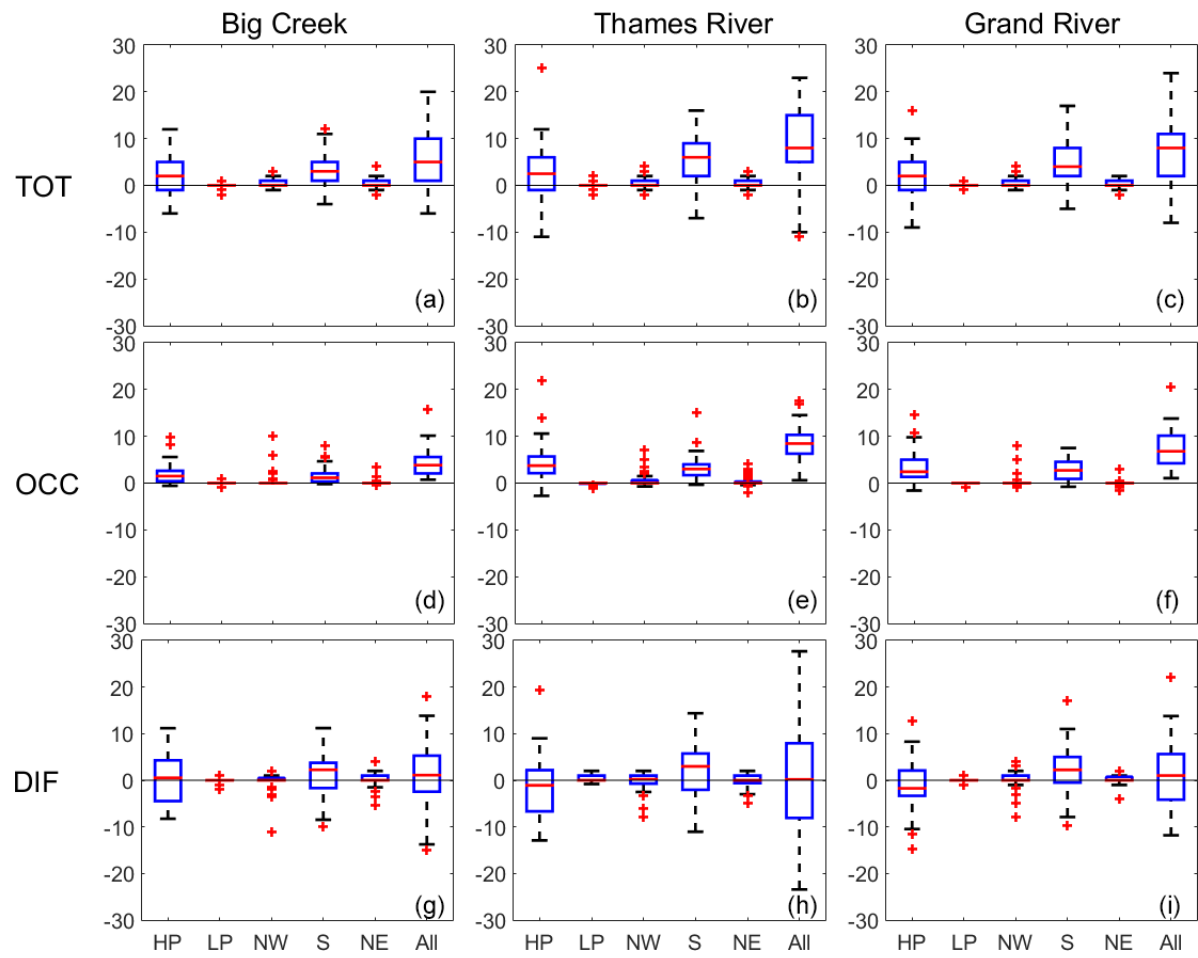

Figure 9. Upper panels: distribution of change in number of high flows between 1961-1990 and 2026-2055 simulated from the 50 members of the ensemble (TOT). Middle panels: distribution of theoretical change in number of high flows using the factor of change in number of heavy rain and warm events between 1961-1990 and 2026-2055 (OCC). Lower panels: TOT minus OCC (DIF). Boxes extend from the 25th to the 75th percentile, with a horizontal red bar showing the median value. The whiskers are lines extending from each end of the box to the 1.5 interquartile range. Plus signs correspond to outliers.
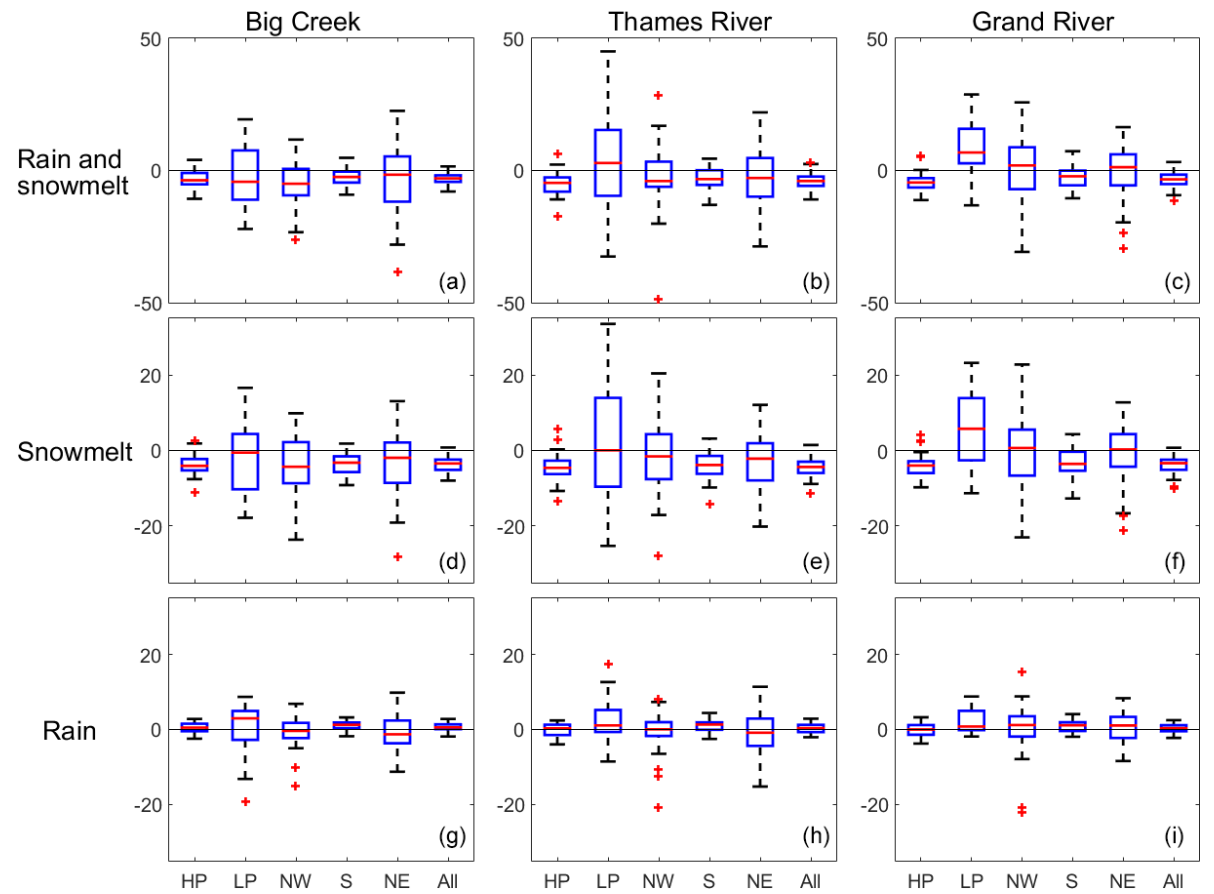

$-50$
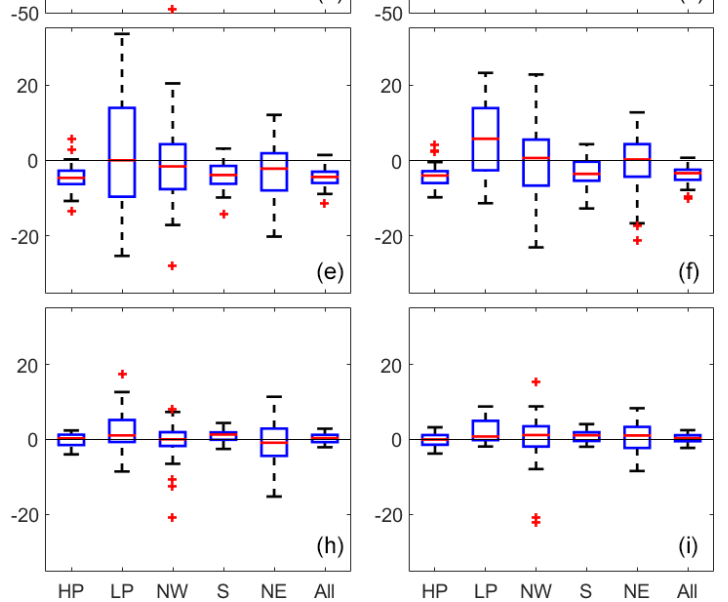

Figure 10. Distribution of simulated change in rain and snowmelt amounts (mm water equivalent) for all compound extreme events between 1961-1990 and 2026-2055 from the 50 members of the ensemble. 


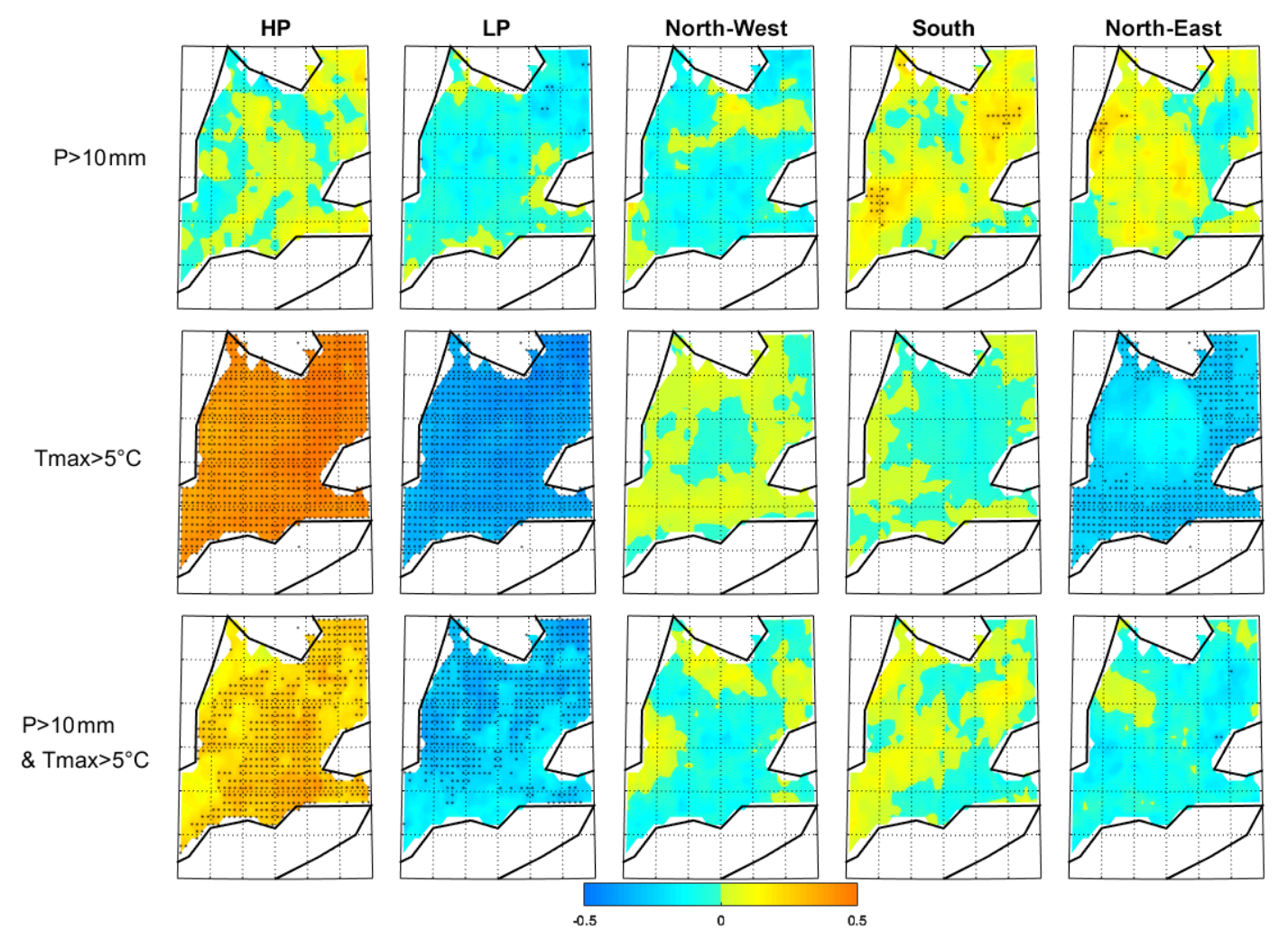

Figure 11. DJF inter-member correlations between change in occurrence of weather regimes and change in number of events between 19611990 and 2026-2055. Black points indicate a correlation significant at $95 \%$ according to the Pearson correlation table.

The correlations with the change in number of high flows in each watershed have also been investigated (Table 2) and show significance in the Big Creek and Grand River watersheds. In both watersheds, LP and a combination LP-NorthWest are negatively correlated with high flows, while a combination North-West-South is positively correlated with high flows. In the Grand River, the number of high flows is also negatively correlated with a combination of HP-LP regime.

The change of heavy precipitation, warm and compound events frequency with respect to change in occurrence of the South, HP, LP and North-East regimes for each member of the ensemble is shown in Fig. 12. The correspondence between change in the number of heavy precipitations events and change in the number of occurrences of weather regimes is not clear, confirming the low correlations in Fig. 11 and Table 1. Regarding the warm events, the large increase in occurrence of HP-South regime or large decrease in the LPNorth-East regimes are generally associated with a large increase in the number of warm events, confirming the results from Fig. 11 and Table 1. Concerning the compound index, a high increase of HP and South occurrences does not systematically lead to a large increase in the number of events (Fig. 12).

\section{Discussion}

\subsection{Atmospheric circulation and extreme weather events}

The extreme weather events investigated in this study were identified from data that have been bias corrected by an univariate method (Ines and Hansen, 2006) that can potentially increase the simulation bias for variables depending equally strongly on more than one climatic driver (Zscheischler et al., 2019). In our study, the number of warm events was clearly overestimated in a large area of the domain (Fig. 5), but the bias-corrected data satisfactorily recreated the number of heavy precipitation and number of compound events (Figs. 4 and 6). Despite the remaining biases in the simulated data, the bias correction improved the results compared to analysis using raw data (Figs. S1 and S2 in the Supplement). This univariate bias-correction method has been chosen in this study because it was satisfactorily used in previous works in the region (Champagne et al., 2019b; Wazneh et al., 2017). Future studies should consider using multivariate bias-corrected methods to further improve the simulation of compound indices.

The occurrence of heavy rain and warm events calculated from bias-corrected temperature and precipitation data is modulated by specific atmospheric patterns in winter, which corroborates previous studies in the Great Lakes region. 

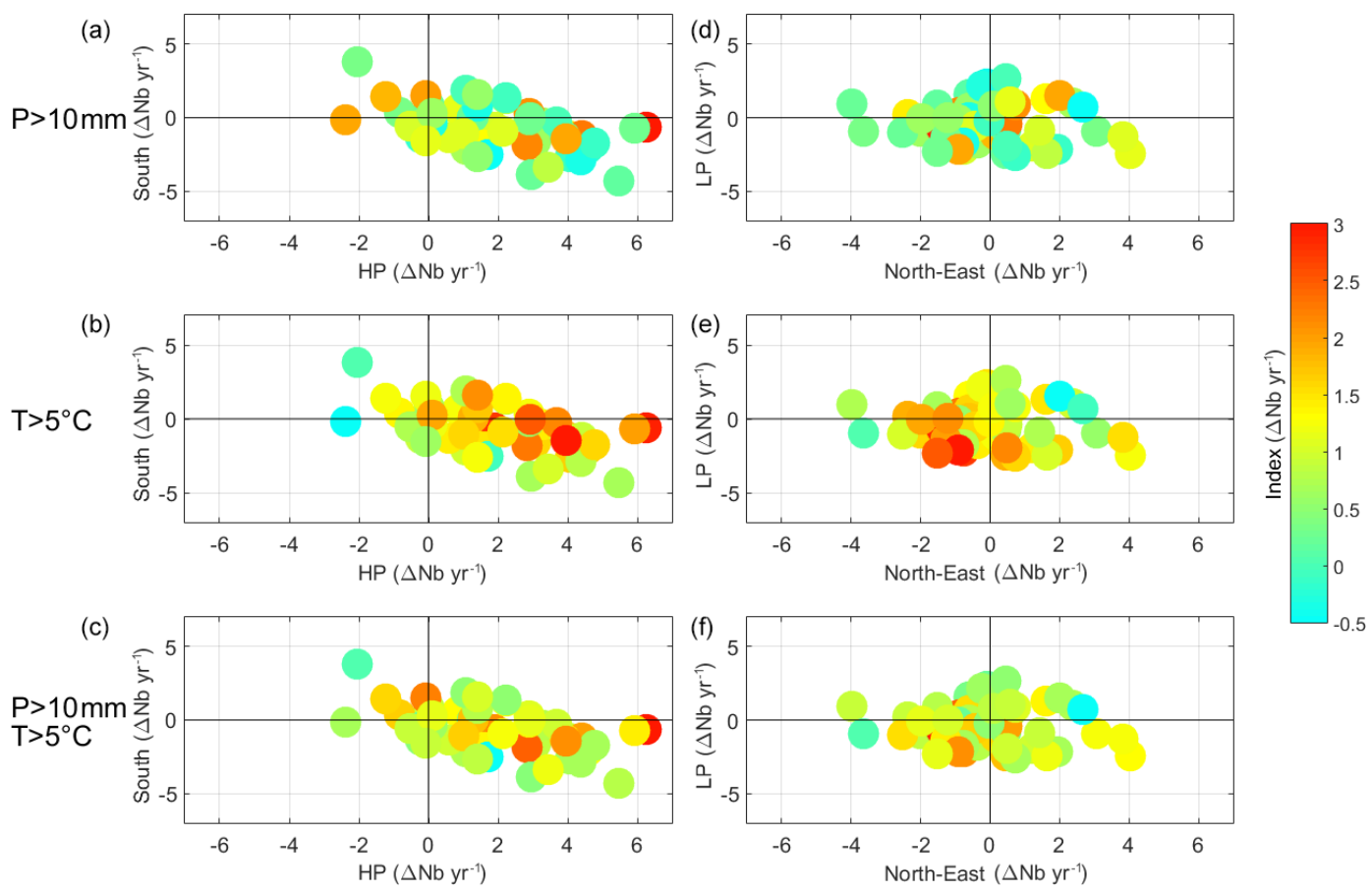

Figure 12. DJF change in occurrences of regimes HP-South (a-c) and LP-North-East (d-f) with respect to the change in number of heavy rain and warm events (colours) for each member of CRCM5-LE between 1961-1990 and 2026-2055.

These studies found that heavy precipitation and flooding events are associated with high geopotential height anomalies on the east coast of North America, similarly to the HP or South regimes (Mallakpour and Villarini, 2016; Zhang and Villarini, 2019; Farnham et al., 2018). Our results found differences between observations and simulations with more heavy precipitation events during the HP regime in the observations, while the simulations with CRCM5-LE show more precipitation events during the South regime (Fig. 4). The overestimation of the number of precipitation events for the South regime can be associated with the difference in pattern between regimes calculated with 20thCR and CanESM2LE (Fig. 3). The South regime calculated with CanESM2LE shows $Z_{500}$ anomalies shifted to the west and likely a more meridional flux compared to the South regime from 20 thCR. The weather regimes associated with heavy precipitations in the mid-west defined by Zhang and Villarini (2019) show high pressure anomalies on the east and low pressure on the west sides of the Great lakes similarly to the South regime calculated with CanESM2-LE. The South regime calculated with 20thCR shows negative $Z_{500}$ anomalies with a northern position compared to CanESM2-LE and therefore a stronger zonal flux while the South regime calculated with CanESM2-LE has likely a more meridional flux driving humidity from the Gulf of Mexico (Fig. 3). This pattern also brings warm temperature events even though the HP regime brings even more warm events in both the observations and the ensemble average (Fig. 5). The HP regime has similar- ities to the positive phase of the NAO, previously associated with warm winter temperature in the Great Lakes region (Ning and Bradley, 2015). The other weather regimes bring generally fewer heavy precipitation or warm events, apart from the LP regime bringing heavy precipitation close to Lake Huron (Fig. 4). LP is not associated with warm events (Fig. 5), suggesting that these extreme precipitations are in the form of snow and likely from lake effect snow. Suriano and Leathers (2017) show that low pressure anomalies northeast of the Great Lakes bring major lake effect snow to the eastern shores of Lake Huron due to less zonal wind and cold outbreaks from the Arctic. The LP regime shows low geopotential height anomalies right on the Great Lakes, and the associated north-west winds on Lake Huron are likely to bring lake effect snowfall in this area.

\subsection{Future evolution of rain and warm events}

The future increase in winter heavy precipitation events in southern Ontario was already described in Deng et al. (2016). Compound events such as ROS events have also been investigated by Jeong and Sushama (2018). These authors defined ROS events as liquid precipitation and snow cover higher than $1 \mathrm{~mm}$ and found no significant trend of ROS events in the Great Lakes region, in continuity to what was observed in the past (Wachowicz et al., 2019). These studies show that the Great Lakes region is located between a region of increased ROS events due to increase of rainfall in the north and a decrease in ROS events due to a decrease of snow- 
pack in southern regions. An increase of rainfall and decrease of snowpack are both expected to occur in southern Ontario (Fig. 10) and are likely to cancel each other in terms of ROS events. Our heavy rain and warm index does not consider snowpack and is expecting to be more frequent in the future (Fig. 8). The increase of heavy rain and warm events is likely driven by warmer temperature shown by the increase of the compound events and warm events both occurring at a higher extent close to Lake Erie (Fig. 8). The increase in extreme precipitation events is less significant than the increase in warm events and occurs mostly in the northern parts of the area (Fig. 8).

The future evolution of ROS or heavy rain and warm events corresponding to different weather patterns has not been yet investigated in previous literature. It is interesting to note that the future increase in the number of heavy rain and warm events is expected to occur only for the HP and South regimes, with the number of events remaining very low for the other regimes (Fig. 8). This result suggests that the global increase of mean temperature and precipitation is not sufficient to reach the $10 \mathrm{~mm}$ and $5^{\circ} \mathrm{C}$ threshold for the LP, North-West and North-East regimes. More precipitation events are expected during the LP regime but the temperature stays too low to increase the numbers of heavy rain and warm events (Fig. 8). The North-West and North-East regimes show an increase of warm events but not an increase in precipitation events and therefore the number of rain and warm events is not expected to increase.

\subsection{Change in frequency of heavy rain and warm events partially modulated by the occurrence of weather regimes}

Despite clear association between the HP-South regimes and occurrences of rain and warm events, the uncertainties linked to internal variability of climate are not fully driven by the frequency of weather regimes. Members of the ensemble associated with a simultaneous high increase of the HP and South regime frequencies are generally associated with higher increase in rainfall and warm events (Table 1), but the association is less straightforward than suggested by the correlation values (Fig. 12), probably due to poor association between precipitation extremes and occurrence of weather regimes (Table 1 and Fig. 11). Similar change in the occurrence of the HP-South weather regimes can lead to variable change in number of heavy rain and warm events (Fig. 12). This suggests that scales other than the weather regimes calculated in the north-eastern North American domain are likely to play a role in weather extreme events and especially the change of heavy rain and warm events and precipitation events. The presence of the Great Lakes has a large role in the variability of precipitation at a local scale (Martynov et al., 2012), suggesting that variability of precipitation events does not depend so much on the atmospheric circulation over the Great Lakes on the day of the events. The temperature of the lakes and the amount of ice covering the lakes play for example a great role in the variability of precipitation (Martynov et al., 2012).

\subsection{Non-stationarity in the relationship between weather extreme events and high flows}

The projections show that the increase in the number of high flows associated with an HP regime is expected to be lower than the increase in the number of heavy rain and warm events (negative DIF in Fig. 9). This result suggests that the conditions that produce high flows may change in the future. As the temperature increases, snowmelt is expected to be a less important component in the generation of high flows in the region (Fig. 10). In the historical period, the HP and South regimes produce approximately the same number of high flows in the simulations (Fig. 7) but are driven mostly by heavy precipitation for the South regime and warm events for the HP regime (Figs. 4 and 5). More importantly, HP shows a further increase of warm events in the future, while South shows rather an increase of precipitation (Fig. 8). In the context of less snow, the importance of precipitation to drive high flows will be higher in the future because warmer conditions do not increase snowmelt in the event of a snowpack reduction (Fig. 10). Therefore, the increase of weather extreme events associated with the South regime will generate an increase of high flows more strenuously than the increase of events associated with the HP regime (Fig. 9).

The future change in the number of high flows is associated with a large inter-member uncertainty (Fig. 9). The weather extreme event inter-member uncertainty was partly associated with the change in occurrence of weather regimes especially for the warm component (Figs. 11 and 12 and Table 1). The association between occurrence of weather regimes and high flows is less clear and shows opposite results (Tables 1 and 2). Especially the change of occurrence of the North-West regime is positively correlated with the change in number of high flows in the Big Creek and Grand River watersheds (Table 2), while it is negatively correlated with the change in the number of weather extreme events in this area (Fig. 11). The correlation is even significant when the North-West and South regimes are associated (Table 2). This result could be due to the preferential sequence of weather regimes and more snow generated by patterns similar to the North-West regime (Champagne et al., 2019b). The pattern associated with North-West regime shows anticyclonic systems in the western part of the domain (Fig. 3). The meteorological systems have a tendency to move eastward, and this anticyclonic system is likely to become a South regime or HP (Champagne et al., 2019a; Table S2 in the Supplement). In addition, as already stated in the previous paragraph, the HP regime will be less likely to produce a heavy rain event than a South regime in the future. Therefore, members projecting an increase in the combination of the snowy North-West regime and wetter and warmer South 
regime are more likely to project more high-flow events. These results emphasize the need to study not only each hydrometeorological extreme events and relationship with atmospheric circulation independently but to also focus on the sequence of weather patterns preceding the high-flow events.

\subsection{Relevance of rain and warm events to explain future evolution of high flows}

Our method, which uses an index based on daily temperature and precipitation to study the future evolution of high flows, is questionable. Even if a heavy rain and warm event is a necessary condition to create a high-flow event (Fig. 2), such an event is not systematically followed by a high-flow event (Fig. 7). The previous section suggests that snow-falling days before the high-flow event have an important role in the generation of high flows. Other factors such as multi-day rain events could also contribute to increase the streamflow. This study focused on single-day events to introduce the first results in the ability of CRCM5-LE to recreate extreme events in southern Ontario, but future studies should investigate multi-day events.

Moreover, as stated in the previous section, the relationship between the extreme weather event index and high flows is affected by non-stationarity. Applied in the past, the rain and warm index works well to define the high-flow risk in southern Ontario (Fig. 2), the warm component of this index being a condition to trigger snowmelt. In a warming climate, snowpack is reduced, and the rain-to-snow ratio increases (Jeong and Sushama, 2018), changing the relationship between extreme weather events and high flows.

To integrate snow processes and reduce the uncertainties from non-stationarity of temperature, the ROS index could be used in lieu of our heavy rain and warm index. However, this index is not projected to be more frequent in the future in the Great Lakes region, precisely because of less snow in the ground (Jeong and Sushama, 2018). Moreover, the ROS index integrates events with a very small contribution of snowmelt to the high flows while neglecting rainfall-only events (Cohen et al., 2015; Jeong and Sushama, 2018; Pradhanang et al., 2013). The definition of ROS also introduces more uncertainties, as it depends on the combination of simulated precipitation and temperature for several days (Kudo et al., 2017). Our heavy rain and warm index minimizes this uncertainty and takes into consideration heavy rainfall regardless of the amount of snow covering the ground. It is therefore a good tool to assess the potential risk of high flows in southern Ontario from all ranges of rain events, even though it is important to keep in mind that the flood risk diminished as snowpack decreases. A rain-only index could also be used but the impact of snowpack on streamflow would be completely eradicated, while snow would still play a role in the future hydrology. ROS events, liquid precipitation events and our heavy rain and warm events, ideally with multi-day events integrated, should be investigated together to fully un- derstand the future evolution of the flood risk due to a shift in weather extreme events.

\section{Conclusion}

The aim of this study was to assess the ability of the Canadian Regional Climate Model large ensemble (CRCM5-LE), a downscaled version of the 50-member global Canadian model large ensemble (CanESM2-LE), to simulate winter hydrometeorological extreme events in southern Ontario and to investigate how the internal variability of climate will modulate the future evolution of these extremes. The winter compound index heavy rain and warm temperature was identified in the past with gridded observation data (NRCANmet) by investigating what conditions of temperature and precipitation are necessary to produce a high flow in three watersheds in southern Ontario. The PRMS model was used to simulate the future evolution of high flows for each member of CRCM5-LE in these three watersheds. The large-scale circulation patterns corresponding to these events were assessed by identifying past recurrent weather regimes based on daily $Z_{500}$ from the 20th century reanalyses and estimating the evolution of the same weather regimes in the future for each member of CanESM2-LE. The results of this study show that CRCM5-LE was able to

1. recreate the historical larger number of events close to Lake Erie despite an overestimation of warm events;

2. simulate more heavy rain and warm events as well as high flows during the regimes associated with high pressure anomalies on the Great Lakes (HP) and the Atlantic Ocean (South); and

3. project an increase in the future number of heavy rain and warm events and associated high flows especially during the HP and South regimes and in the vicinity of Lake Erie.

These results suggest that depending on the future evolution of natural variability of climate, the increase in the number of events will be amplified or attenuated by the favoured positions of the pressure systems. The natural variability of climate is not expected to greatly modulate the number of high flows due to an increase of the importance of precipitation in generating high flows. The role of more localized processes such as impact of the lakes on precipitation events needs to be further evaluated to improve the ability of the next versions of regional climate models to recreate the precipitation events. The newly created weather index did not integrate snowpack because the uncertainties in the ability of CRCM5$\mathrm{LE}$ to recreate precipitation and temperature extremes on a daily basis would be further increased in snowmelt estimates. However, snowpack variability will have a large impact in the modulation of high flows in the region, and future studies should investigate snow processes by taking advantage 
of rapid improvements in climate regional modelling. Other regional climate models and different scenarios should also be used to improve our understanding of the future evolution of hydrometeorological extreme events in southern Ontario. Despite these future possible improvements, our study gives a good estimation of what to expect in terms of change in number of hydrometeorological events in southern Ontario and will serve to better estimate the future flood risk in this populated region.

Data availability. The historical hydrometric data can be extracted from the Environment and Climate Change Canada Historical Hydrometric Data website (https://wateroffice.ec.gc.ca/mainmenu/ historical_data_index_e.html, last access: 3 February 2020) (Environment and Climate Change Canada, 2020). PRMS model codes are accessible from the USGS website (https://www.usgs. gov/software/precipitation-runoff-modeling-system-prms, last access: 24 March 2020) (USGS, 2020). CRCM5-LE data are not publicly available. Martin Leduc should be contacted for any request (leduc.martin@ouranos.ca). Model simulations and sequences of weather regimes are available upon request from M. Altaf Arain (arainm@mcmaster.ca).

Supplement. The supplement related to this article is available online at: https://doi.org/10.5194/esd-11-301-2020-supplement.

Author contributions. ML furnished CRCM5-LE data. OC performed the analyses and made the figures. OC prepared the manuscript with contributions from all co-authors.

Competing interests. The authors declare that they have no conflict of interest.

Special issue statement. This article is part of the special issue "Large Ensemble Climate Model Simulations: Exploring Natural Variability, Change Signals and Impacts". It is not associated with a conference.

Acknowledgements. We are acknowledging the reviewers who gave constructive comments during the publication process. Financial support for this study was provided by the Natural Sciences and Engineering Research Council (NSERC) of Canada through the FloodNet Project. We also acknowledge support and contributions from Global Water Future Program, Environment and Climate Change Canada, Natural Resources Canada and Water Survey of Canada. The production of ClimEx was funded within the ClimEx project by the Bavarian State Ministry for the Environment and Consumer Protection. CRCM5 was developed by the ESCER centre of Université du Québec à Montréal (UQAM) in collaboration with Environment and Climate Change Canada. We acknowledge Environment and Climate Change Canada's Canadian Centre for Climate Modelling and Analysis for executing and making avail- able the CanESM2 large ensemble simulations used in this study, and the Canadian Sea Ice and Snow Evolution Network for proposing the simulations. Computations with CRCM5 for the ClimEx project were made on the SuperMUC supercomputer at Leibniz Supercomputing Centre (LRZ) of the Bavarian Academy of Sciences and Humanities. The operation of this supercomputer is funded via the Gauss Centre for Supercomputing (GCS) by the German Federal Ministry of Education and Research and the Bavarian State Ministry of Education, Science and the Arts.

Financial support. This research has been supported by the NSERC (grant no. NETGP 451456).

Review statement. This paper was edited by Nicola Maher and reviewed by two anonymous referees.

\section{References}

Buttle, J. M., Allen, D. M., Caissie, D., Davison, B., Hayashi, M., Peters, D. L., Pomeroy, J. W., Simonovic, S., StHilaire, A., and Whitfield, P. H.: Flood processes in Canada: Regional and special aspects, Can. Water Resour. J./Revue canadienne des ressources hydriques, 41, 7-30, https://doi.org/10.1080/07011784.2015.1131629, 2016.

Champagne, O., Arain, M. A., and Coulibaly, P.: Atmospheric circulation amplifies shift of winter streamflow in Southern Ontario, J. Hydrol., 578, 124051, https://doi.org/10.1016/j.jhydrol.2019.124051, 2019a.

Champagne, O., Arain, A., Leduc, M., Coulibaly, P., and McKenzie, S.: Future shift in winter streamflow modulated by internal variability of climate in southern Ontario, Hydrol. Earth Syst. Sci. Discuss., https://doi.org/10.5194/hess-2019-204, in review, 2019b.

Cohen, J., Ye, H., and Jones, J.: Trends and variability in rain-onsnow events: RAIN-ON-SNOW, Geophys. Res. Lett., 42, 71157122, https://doi.org/10.1002/2015GL065320, 2015.

Compo, G. P., Whitaker, J. S., Sardeshmukh, P. D., Matsui, N., Allan, R. J., Yin, X., Gleason, B. E., Vose, R. S., Rutledge, G., Bessemoulin, P., Brönnimann, S., Brunet, M., Crouthamel, R. I., Grant, A. N., Groisman, P. Y., Jones, P. D., Kruk, M. C., Kruger, A. C., Marshall, G. J., Maugeri, M., Mok, H. Y., Nordli, Ø., Ross, T. F., Trigo, R. M., Wang, X. L., Woodruff, S. D., and Worley, S. J.: The twentieth century reanalysis project, Q. J. Roy. Meteorol. Soc., 137, 1-28, https://doi.org/10.1002/qj.776, 2011.

Deng, Z., Qiu, X., Liu, J., Madras, N., Wang, X., and Zhu, H.: Trend in frequency of extreme precipitation events over Ontario from ensembles of multiple GCMs, Clim. Dynam., 46, 2909-2921, https://doi.org/10.1007/s00382-015-2740-9, 2016.

Deser, C., Phillips, A. S., Alexander, M. A., and Smoliak, B. V.: Projecting North American climate over the next 50 years: uncertainty due to internal variability, J. Climate, 27, 2271-2296, 2014.

Dressler, K. A., Leavesley, G. H., Bales, R. C., and Fassnacht, S. R.: Evaluation of gridded snow water equivalent and satellite snow cover products for mountain basins in a hydrologic model, Hy- 
drol. Process., 20, 673-688, https://doi.org/10.1002/hyp.6130, 2006.

Environment and Climate Change Canada: Historical Hydrometric Data - Water Level and Flow, available at: https://wateroffice. ec.gc.ca/mainmenu/historical_data_index_e.html, last access: 3 February 2020.

Farnham, D. J., Doss-Gollin, J., and Lall, U.: Regional Extreme Precipitation Events: Robust Inference From Credibly Simulated GCM Variables, Water Resour. Res., 54, 3809-3824, https://doi.org/10.1002/2017WR021318, 2018.

Freudiger, D., Kohn, I., Stahl, K., and Weiler, M.: Large-scale analysis of changing frequencies of rain-on-snow events with floodgeneration potential, Hydrol. Earth Syst. Sci., 18, 2695-2709, https://doi.org/10.5194/hess-18-2695-2014, 2014.

Fyfe, J. C., Derksen, C., Mudryk, L., Flato, G. M., Santer, B. D., Swart, N. C., Molotch, N. P., Zhang, X., Wan, H., Arora, V. K., Scinocca, J., and Jiao, Y.: Large near-term projected snowpack loss over the western United States, Nat. Commun., 8, 14996, https://doi.org/10.1038/ncomms14996, 2017.

Hoegh-Guldberg, O., Jacob, D., Taylor, M., Bindi, M., Brown, S., Camilloni, I., Diedhiou, A., Djalante, R., Ebi, K. L., Engelbrecht, F., Guiot, J., Hijioka, Y., Mehrotra, S., Seneviratne, S. I., Thomas, A., Warren, R., Halim, S. A., Achlatis, M., Alexander, L. V., Berry, P., Boyer, C., Byers, E., Brilli, L., Buckeridge, M., Cheung, W., Craig, M., Evans, J., Fischer, H., Fraedrich, K., Ganase, A., Gattuso, J. P., Bolaños, T. G., Hanasaki, N., Hayes, K., Hirsch, A., Jones, C., Jung, T., Kanninen, M., Krinner, G., Lawrence, D., Ley, D., Liverman, D., Mahowald, N., Meissner, K. J., Millar, R., Mintenbeck, K., Mix, A. C., Notz, D., Nurse, L., Okem, A., Olsson, L., Oppenheimer, M., Paz, S., Petersen, J., Petzold, J., Preuschmann, S., Rahman, M. F., Scheuffele, H., Schleussner, C.-F., Séférian, R., Sillmann, J., Singh, C., Slade, R., Stephenson, K., Stephenson, T., Tebboth, M., Tschakert, P., Vautard, R., Wehner, M., Weyer, N. M., Whyte, F., Yohe, G., Zhang, X., Zougmoré, R. B., Marengo, J. A., Pereira, J., and Sherstyukov, B.: Impacts of $1.5^{\circ} \mathrm{C}$ of Global Warming on Natural and Human Systems, in: An IPCC Special Report on the impacts of global warming of $1.5^{\circ} \mathrm{C}$ above pre-industrial levels and related global greenhouse gas emission pathways, in the context of strengthening the global response to the threat of climate change, sustainable development, and efforts to eradicate poverty, 2018.

Ines, A. V. M. and Hansen, J. W.: Bias correction of daily GCM rainfall for crop simulation studies, Agr. Forest Meteorol., 138, 44-53, https://doi.org/10.1016/j.agrformet.2006.03.009, 2006.

Jeong, D. and Sushama, L.: Rain-on-snow events over North America based on two Canadian regional climate models, Clim. Dynam., 50, 303-316, https://doi.org/10.1007/s00382-017-3609-x, 2018.

Kharin, V. V., Zwiers, F. W., Zhang, X., and Wehner, M.: Changes in temperature and precipitation extremes in the CMIP5 ensemble, Climatic Change, 119, 345-357, https://doi.org/10.1007/s10584013-0705-8, 2013.

Kudo, R., Yoshida, T., and Masumoto, T.: Uncertainty analysis of impacts of climate change on snow processes: Case study of interactions of GCM uncertainty and an impact model, J. Hydrol., 548, 196-207, https://doi.org/10.1016/j.jhydrol.2017.03.007, 2017.
Lafaysse, M., Hingray, B., Mezghani, A., Gailhard, J., and Terray, L.: Internal variability and model uncertainty components in future hydrometeorological projections: The Alpine Durance basin, Water Resour. Res., 50, 3317-3341, https://doi.org/10.1002/2013WR014897, 2014.

Leduc, M., Mailhot, A., Frigon, A., Martel, J.-L., Ludwig, R., Brietzke, G. B., Giguère, M., Brissette, F., Turcotte, R., Braun, M., and Scinocca, J.: The ClimEx Project: A 50-Member Ensemble of Climate Change Projections at 12-km Resolution over Europe and Northeastern North America with the Canadian Regional Climate Model (CRCM5), J. Appl. Meteorol. Clim., 58, 663693, https://doi.org/10.1175/JAMC-D-18-0021.1, 2019.

Leonard, M., Westra, S., Phatak, A., Lambert, M., van den Hurk, B., McInnes, K., Risbey, J., Schuster, S., Jakob, D., and Stafford-Smith, M.: A compound event framework for understanding extreme impacts: A compound event framework, Wiley Interdisciplin. Rev.: Clim. Change, 5, 113-128, https://doi.org/10.1002/wcc.252, 2014.

Liao, C. and Zhuang, Q.: Quantifying the Role of Snowmelt in Stream Discharge in an Alaskan Watershed: An Analysis Using a Spatially Distributed Surface Hydrology Model: Role Of Snowmelt In Streamflow In Alaska, J. Geophys. Res.-Earth, 122, 2183-2195, https://doi.org/10.1002/2017JF004214, 2017.

Lorenz, E. N.: Deterministic Nonperiodic Flow, J. Atmos. Sci., 20, 130-141, https://doi.org/10.1175/15200469(1963)020<0130:DNF>2.0.CO;2, 1963.

Mallakpour, I. and Villarini, G.: Investigating the relationship between the frequency of flooding over the central United States and large-scale climate, Adv. Water Resour., 92, 159-171, https://doi.org/10.1016/j.advwatres.2016.04.008, 2016.

Markstrom, S. L., Regan, R. S., Hay, L. E., Viger, R. J., Webb, R. M. T., Payn, R. A., and LaFontaine, J. H.: PRMS-IV, the Precipitation-Runoff Modeling System, Version 4: Tech. and Methods 6-B7, US Geol. Surv., Reston, VA, 2015.

Martynov, A., Sushama, L., Laprise, R., Winger, K., and Dugas, B.: Interactive lakes in the Canadian Regional Climate Model, version 5: the role of lakes in the regional climate of North America, Tellus A, 64, 16226, https://doi.org/10.3402/tellusa.v64i0.16226, 2012.

Mastin, M. C., Chase, K. J., and Dudley, R. W.: Changes in Spring Snowpack for Selected Basins in the United States for Different Climate-Change Scenarios, Earth Interact., 15, 1-18, https://doi.org/10.1175/2010EI368.1, 2011.

McCabe, G. J., Clark, M. P., and Hay, L. E.: Rain-on-Snow Events in the Western United States, B. Am. Meteorol. Soc., 88, 319328, https://doi.org/10.1175/BAMS-88-3-319, 2007.

McKenney, D. W., Hutchinson, M. F., Papadopol, P., Lawrence, K., Pedlar, J., Campbell, K., Milewska, E., Hopkinson, R. F., Price, D., and Owen, T.: Customized Spatial Climate Models for North America, B. Am. Meteorol. Soc., 92, 1611-1622, https://doi.org/10.1175/2011BAMS3132.1, 2011.

Merz, R. and Blöschl, G.: A process typology of regional floods: Process Typology Of Regional Floods, Water Resour. Res., 39, 1340, https://doi.org/10.1029/2002WR001952, 2003.

Michelangeli, P.-A., Vautard, R., and Legras, B.: Weather Regimes: Recurrence and Quasi Stationarity, J. Atmos. Sci., 52, 1237-1256, https://doi.org/10.1175/15200469(1995)052<1237:WRRAQS>2.0.CO;2, 1995. 
Musselman, K. N., Lehner, F., Ikeda, K., Clark, M. P., Prein, A. F., Liu, C., Barlage, M., and Rasmussen, R.: Projected increases and shifts in rain-on-snow flood risk over western North America, Nat. Clim. Change, 8, 808-812, https://doi.org/10.1038/s41558018-0236-4, 2018.

Ning, L. and Bradley, R. S.: Winter climate extremes over the northeastern United States and southeastern Canada and teleconnections with large-scale modes of climate variability, J. Climate, 28, 2475-2493, 2015.

Pradhanang, S. M., Frei, A., Zion, M., Schneiderman, E. M., Steenhuis, T. S., and Pierson, D.: Rain-on-snow runoff events in New York: Rain-On-Snow Events In New York, Hydrol. Process., 27, 3035-3049, https://doi.org/10.1002/hyp.9864, 2013.

Scott, R. W. and Huff, F. A.: Impacts of the Great Lakes on regional climate conditions, J. Great Lakes Res., 22, 845-863, 1996.

Sigmond, M., Fyfe, J. C., and Swart, N. C.: Ice-free Arctic projections under the Paris Agreement, Nat. Clim. Change, 8, 404-408, https://doi.org/10.1038/s41558-018-0124-y, 2018.

Surfleet, C. G. and Tullos, D.: Variability in effect of climate change on rain-on-snow peak flow events in a temperate climate, J. Hydrol., 479, 24-34, https://doi.org/10.1016/j.jhydrol.2012.11.021, 2013.

Surfleet, C. G., Tullos, D., Chang, H., and Jung, I.-W.: Selection of hydrologic modeling approaches for climate change assessment: A comparison of model scale and structures, J. Hydrol., 464-465, 233-248, https://doi.org/10.1016/j.jhydrol.2012.07.012, 2012.

Suriano, Z. J. and Leathers, D. J.: Synoptic climatology of lakeeffect snowfall conditions in the eastern Great Lakes region: Synoptic Climatology Of Lake-Effect Snowfall Conditions, Synoptic Climatology Of Lake-Effect Snowfall Conditions, Int. J. Climatol., 37, 4377-4389, https://doi.org/10.1002/joc.5093, 2017.

Teng, F., Huang, W., Cai, Y., Zheng, C., and Zou, S.: Application of Hydrological Model PRMS to Simulate Daily Rainfall Runoff in Zamask-Yingluoxia Subbasin of the Heihe River Basin, Water, 9, 769, https://doi.org/10.3390/w9100769, 2017.

Teng, F., Huang, W., and Ginis, I.: Hydrological modeling of storm runoff and snowmelt in Taunton River Basin by applications of HEC-HMS and PRMS models, Nat. Hazards, 91, 179-199, https://doi.org/10.1007/s11069-017-3121-y, 2018.

Thiombiano, A. N., El Adlouni, S., St-Hilaire, A., Ouarda, T. B. M. J., and El-Jabi, N.: Nonstationary frequency analysis of extreme daily precipitation amounts in Southeastern Canada using a peaks-over-threshold approach, Theor. Appl. Climatol., 129, 413-426, https://doi.org/10.1007/s00704-016-1789-7, 2017.
Trenberth, K. E.: Conceptual Framework for Changes of Extremes of the Hydrological Cycle with Climate Change, Climatic Change, 42, 327-339, https://doi.org/10.1023/A:1005488920935, 1999.

USGS: Precipitation Runoff Modeling System (PRMS), available at: https://www.usgs.gov/software/ precipitation-runoff-modeling-system-prms, last access: 24 March 2020.

Wachowicz, L. J., Mote, T. L., and Henderson, G. R.: A rain on snow climatology and temporal analysis for the eastern United States, Phys. Geogr., 41, 54-69, https://doi.org/10.1080/02723646.2019.1629796, 2019.

Wazneh, H., Arain, M. A., and Coulibaly, P.: Historical Spatial and Temporal Climate Trends in Southern Ontario, Canada, J. Appl. Meteorol. Clim., 56, 2767-2787, https://doi.org/10.1175/JAMCD-16-0290.1, 2017.

Würzer, S., Jonas, T., Wever, N., and Lehning, M.: Influence of Initial Snowpack Properties on Runoff Formation during Rain-on-Snow Events, J. Hydrometeorol., 17, 1801-1815, https://doi.org/10.1175/JHM-D-15-0181.1, 2016.

Zhang, W. and Villarini, G.: On the weather types that shape the precipitation patterns across the U.S. Midwest, Clim. Dynam., 53, 4217-4232, https://doi.org/10.1007/s00382-019-04783-4, 2019.

Zhang, X., Alexander, L., Hegerl, G. C., Jones, P., Tank, A. K., Peterson, T. C., Trewin, B., and Zwiers, F. W.: Indices for monitoring changes in extremes based on daily temperature and precipitation data, Wiley Interdisciplin. Rev.: Clim. Change, 2, 851870, https://doi.org/10.1002/wcc.147, 2011.

Zhao, H., Higuchi, K., Waller, J., Auld, H., and Mote, T.: The impacts of the PNA and NAO on annual maximum snowpack over southern Canada during 1979-2009, Int. J. Climatol., 33, 388395, https://doi.org/10.1002/joc.3431, 2013.

Zscheischler, J., Fischer, E. M., and Lange, S.: The effect of univariate bias adjustment on multivariate hazard estimates, Earth Syst. Dynam., 10, 31-43, https://doi.org/10.5194/esd-1031-2019, 2019. 